\title{
Independent Susceptibility Markers for Atrial Fibrillation on Chromosome 4q25
}

\author{
Steven A. Lubitz, MD, MPH*; Moritz F. Sinner, MD*; Kathryn L. Lunetta, PhD; Seiko Makino, MS; \\ Arne Pfeufer, MD, MSc; Rosanna Rahman, PhD; Caroline E. Veltman, MD; John Barnard, PhD; \\ Joshua C. Bis, PhD; Stephan P. Danik, MD; Akshata Sonni, BS; Marisa A. Shea, BS, RN; \\ Federica del Monte, MD; Siegfried Perz, MSc; Martina Müller, MSc, PhD; Annette Peters, MSc, PhD; \\ Steven M. Greenberg, MD, PhD; Karen L. Furie, MD; Charlotte van Noord, MD; \\ Eric Boerwinkle, $\mathrm{PhD}$; Bruno H.C. Stricker, MB, PhD; Jacqueline Witteman, PhD; \\ Jonathan D. Smith, PhD; Mina K. Chung, MD; Susan R. Heckbert, MD, PhD; \\ Emelia J. Benjamin, MD, ScM; Jonathan Rosand, MD; Dan E. Arking, PhD; \\ Alvaro Alonso, MD, PhD; Stefan Kääb, MD, PhD*; Patrick T. Ellinor, MD, PhD*
}

Background - Genetic variants on chromosome 4q25 are associated with atrial fibrillation (AF). We sought to determine whether there is more than 1 susceptibility signal at this locus.

Methods and Results - Thirty-four haplotype-tagging single-nucleotide polymorphisms (SNPs) at the 4q25 locus were genotyped in 790 case and 1177 control subjects from Massachusetts General Hospital and tested for association with AF. We replicated SNPs associated with AF after adjustment for the most significantly associated SNP in 5066 case and 30661 referent subjects from the German Competence Network for Atrial Fibrillation, Atherosclerosis Risk In Communities Study, Cleveland Clinic Lone AF Study, Cardiovascular Health Study, and Rotterdam Study. All subjects were of European ancestry. A multimarker risk score composed of SNPs that tagged distinct AF susceptibility signals was constructed and tested for association with AF, and all results were subjected to meta-analysis. The previously reported SNP, rs2200733, was most significantly associated with AF (minor allele odds ratio 1.80, 95\% confidence interval 1.50 to $2.15, P=1.2 \times 10^{-20}$ ) in the discovery sample. Adjustment for rs 2200733 genotype revealed 2 additional susceptibility signals marked by rs17570669 and rs3853445. A graded risk of AF was observed with an increasing number of AF risk alleles at SNPs that tagged these 3 susceptibility signals.

Conclusions - We identified 2 novel AF susceptibility signals on chromosome 4q25. Consideration of multiple susceptibility signals at chromosome 4q25 identifies individuals with an increased risk of AF and may localize regulatory elements at the locus with biological relevance in the pathogenesis of AF. (Circulation. 2010;122:976-984.)

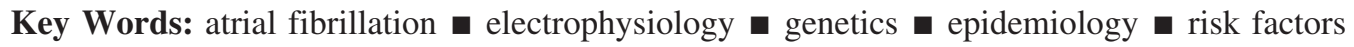

Received October 15, 2009; accepted June 25, 2010.

From the Cardiovascular Research Center (S.A.L., S.M., P.T.E.), Massachusetts General Hospital, Charlestown, Mass; Division of Preventive Medicine (S.A.L.), Brigham and Women's Hospital, Boston, Mass; Department of Medicine I (M.F.S., M.M., S.K.), University Hospital Grosshadern and Institute of Medical Informatics, Biometry and Epidemiology (M.M.), Ludwig Maximilians University, Munich, Germany; National Heart, Lung, and Blood Institute's Framingham Heart Study (K.L.L., E.J.B.), Framingham, Mass; Department of Biostatistics (K.L.L.) and Epidemiology Department (E.J.B.), Boston University School of Public Health, Boston, Mass; Institute of Human Genetics (A. Pfeufer), TU München, Klinikum Rechts der Isar, Munich, Germany; Institute of Human Genetics (A. Pfeufer), Institute for Biological and Medical Imaging (S.P.), and Institute of Epidemiology (M.M., A. Peters), Helmholtz Zentrum München, German Research Center for Environmental Health, Neuherberg, Germany; Stroke Service (R.R., A.S., S.M.G., K.L.F., J.R.) and Cardiac Arrhythmia Service (S.P.D., M.A.S., P.T.E.), Massachusetts General Hospital, Boston, Mass; Department of Epidemiology (C.E.V., C.v.N., B.H.C.S., J.W.), Erasmus Medical Center, Rotterdam, the Netherlands; Department of Quantitative Health Sciences (J.B.), Department of Cell Biology (J.D.S.), and Department of Cardiovascular Medicine (M.K.C.), Heart and Vascular Institute, Department of Molecular Cardiology, Lerner Research Institute, Cleveland Clinic, Cleveland, Ohio; Department of Medicine (J.C.B.), University of Washington, Seattle, Wash; Cardiovascular Research (F.d.M.), Beth Israel Deaconess Medical Center, Boston, Mass; Dutch Medicines Evaluation Board (C.v.N.), the Hague, Netherlands; Human Genetics Center and Institute for Molecular Medicine (E.B.), University of Texas Health Science Center, Houston, Tex; Inspectorate for Health Care (B.H.C.S.), The Hague, Netherlands; Department of Epidemiology (S.R.H.), University of Washington, and Center for Health Studies, Group Health, Seattle, Wash; Cardiology and Preventive Medicine Sections (E.J.B.), Department of Medicine, Boston University School of Medicine, Boston, Mass; McKusick-Nathans Institute of Genetic Medicine (D.E.A.), Johns Hopkins University School of Medicine, Baltimore, Md; and Division of Epidemiology and Community Health (A.A.), School of Public Health, University of Minnesota, Minneapolis.

*Drs Lubitz, Sinner, Kääb, and Ellinor contributed equally to this study.

The online-only Data Supplement is available with this article at http://circ.ahajournals.org/cgi/content/full/CIRCULATIONAHA.109.886440/DC1. Guest Editor for this article was Kari E. North, PhD.

Correspondence to Patrick T. Ellinor, MD, PhD, Cardiac Arrhythmia Service and Cardiovascular Research Center, Massachusetts General Hospital, Boston, MA 02114. E-mail pellinor@partners.org

(C) 2010 American Heart Association, Inc.

Circulation is available at http://circ.ahajournals.org 
A trial fibrillation (AF) is the most common arrhythmia encountered in clinical practice and is associated with substantial morbidity ${ }^{1}$ and societal healthcare costs. ${ }^{2}$ Although many risk factors for AF have been identified, the recognition of a common heritable component underlying $\mathrm{AF}^{3,4}$ indicates that genetic variation may play a role in its pathogenesis.

\section{Clinical Perspective on p 984}

We recently participated in a genome-wide association study that identified a disease-susceptibility locus for AF on chromosome $4 \mathrm{q} 25$ in individuals of European and Asian descent. ${ }^{5}$ We replicated the association between the most significantly associated single-nucleotide polymorphism (SNP), rs2200733, and AF in a subsequent study of 3508 subjects with AF and 12173 control subjects from 4 additional cohorts of European ancestry. ${ }^{6}$ A meta-analysis of the results from both studies revealed an odds ratio (OR) of 1.9 for the rs2200733 risk allele (95\% confidence interval [CI] 1.60 to $\left.2.26, P=3.3 \times 10^{-13}\right){ }^{6}$ We and others have again replicated the chromosome $4 \mathrm{q} 25$ AF susceptibility locus in subsequent genome-wide association studies for AF. ${ }^{7-9}$

In the present study, we sought to identify whether there are multiple AF susceptibility signals at the 4q25 locus in individuals of European ancestry by performing fine mapping of common SNPs in the region and replicating associations in independent study samples. We further sought to determine whether the consideration of multiple markers associated with $\mathrm{AF}$ at this locus could further refine the association signal.

\section{Methods}

\section{Study Samples}

Detailed descriptions of the study cohorts are provided in the online-only Data Supplement. Individuals in the discovery stage of the analysis were drawn from 2 different samples at the Massachusetts General Hospital (MGH) and pooled for analysis. These samples included patients with lone AF referred to the Cardiac Arrhythmia Service starting in June 2001 in whom AF was documented by ECG before 66 years of age and patients with AF by ECG or history who were admitted to the MGH stroke service between January 1998 and July 2006 with an acute ischemic or hemorrhagic stroke. Referent subjects from MGH were from a large $(>18000$ patients) primary care practice serving the hospital catchment area. Absence of $\mathrm{AF}$ was documented through interview and from review of medical records, including all available ECGs.

Genetic variants associated with $\mathrm{AF}$ in the discovery sample after adjustment for the top SNP (see Statistical Analysis) were genotyped in an independent replication study sample composed of subjects from the German Competence Network for Atrial Fibrillation (AFNET), a national registry of AF patients. ${ }^{10} \mathrm{AF}$ was confirmed by ECG, and DNA samples were collected from patients with AF in whom onset occurred before 60 years of age. Referent subjects were derived from a community-based epidemiological survey study conducted between 1999 and 2001 of persons living in or near the city of Augsburg, Germany (Cooperative Health Research in the Region of Augsburg [KORA] S4) and were excluded if they reported a history of AF, had signs or symptoms of AF on physical examination, or had an absence of sinus rhythm on a required ECG. ${ }^{11}$

We performed in silico replication of associations between $\mathrm{AF}$ and SNPs that represented distinct susceptibility signals in MGH and AFNET in 4 additional study samples with previously genotyped subjects. The Atherosclerosis Risk In Communities (ARIC) study is a prospective population-based study of cardiovascular disease in the
United States that consists of participants who were 45 to 64 years old at enrollment. Subjects included in this analysis included those recruited from 3 US communities (suburbs of Minneapolis, Minn; Washington County, Maryland; and Forsyth County, North Carolina) between 1987 and 1989.12 The Cleveland Clinic Lone AF Study (CCAF) is composed of case subjects with $\mathrm{AF}$ in the absence of significant structural heart disease. Referent subjects were population controls from studies 64, 65, 66, and 67 in the Illumina iControl database, a publicly accessible database of genotype and phenotype data from control genome-wide association study populations. The Cardiovascular Health Study (CHS) is a prospective populationbased study of cardiovascular disease in individuals 65 years or older recruited from 4 field centers in the United States (Forsyth County, North Carolina; Sacramento County, California; Washington County, Maryland; and Pittsburgh, Pa). ${ }^{13}$ The Rotterdam Study (RS) is a community-based longitudinal study of elderly individuals from a suburb of Rotterdam, Netherlands, founded in 1990 with a focus on identifying determinants of health and cardiovascular, neurogeriatric, bone, and eye diseases. ${ }^{14}$

Prevalent AF was defined as events that occurred in individuals before that individual's DNA collection in cohort studies and on the basis of AF ascertainment in case-control studies. Incident AF was defined as events that occurred after DNA collection among participants free of AF at DNA collection in cohort studies. Subjects were restricted to those of self-reported European descent.

\section{SNP Selection and Genotyping}

A $200-\mathrm{kb}$ region extending from the PITX2 gene to approximately 50 $\mathrm{kb}$ beyond the previously reported SNP rs2200733 was considered for fine mapping of the chromosome $4 \mathrm{q} 25$ locus. All SNPs on chromosome 4 between positions 111780000 and 111985000 with a minor allele frequency of $5 \%$ or greater were identified from the HapMap CEU data set release 22 (NCBI [National Center for Biotechnology Information] build 36, dbSNP [database of SNPs] build 126). We identified 35 haplotype-tagging SNPs $\left(r^{2} \geq 0.8\right)$ in this region using the Tagger program within Haploview version 4.0. ${ }^{15}$ Additionally, 6 SNPs that were moderately correlated with rs2200733 $\left(r^{2}\right.$ between 0.2 and 0.8$)$ were selected.

We extracted DNA from whole blood of each subject using standard techniques. In the MGH and AFNET samples, genotyping was performed with polymerase chain reaction, iPlex single-base primer extension, and matrix-assisted laser desorption/ionizationtime-of-flight mass spectrometry in a 384-well format (Sequenom, San Diego, Calif) according to the manufacturer's instructions. Data were analyzed with SpectroTYPER 3.4 software, and cluster plots were inspected visually and curated manually to confirm genotyping calls. The genotyping platforms for the remaining cohorts were Affymetrix 6.0 (ARIC; Affymetrix, Santa Clara, Calif), Illumina Hap550 version 3 and Illumina Hap610 version 1 (CCAF cases; Illumina Inc, San Diego, Calif), Illumina Hap550 version 1 or 3 (CCAF referents), Illumina $370 \mathrm{CNV}$ (CHS), and Illumina Infinium HumanHap550 version 3 (RS). Only directly genotyped SNPs were included in the analysis, with the exception of rs17570669 during the replication stage in the CCAF sample. Imputation in CCAF was performed with MACH version 1.0.16 (available at http://www.sph. umich.edu/csg/abecasis/MaCH/index.html from the Center for Statistical Genetics of the University of Michigan) with the HapMap CEU reference panel (NCBI build 36; Rsq 0.6144 for cases and 0.7302 for the iControl database controls). In CHS, genotypes for rs17570669 were imputed with BIMBAM version $0.99,{ }^{16}$ but these were not included in the analyses owing to poor imputation quality (ratio of observed to expected genotype variance of 0.11 ).

The institutional review board or medical ethics committee, as appropriate for each participating institution, approved study procedures. Written informed consent was obtained from all study subjects or their proxies, including consent to use DNA for genetic analyses of cardiovascular disease.

\section{Statistical Analysis}

We tested each SNP included in the discovery stage for deviation from Hardy-Weinberg equilibrium using an exact test ${ }^{17}$ and excluded 
Table 1. Characteristics of Study Subjects

\begin{tabular}{|c|c|c|c|c|c|c|c|c|c|c|c|c|c|c|c|c|}
\hline & & & \multicolumn{14}{|c|}{ Replication Stage } \\
\hline & \multirow{2}{*}{\multicolumn{2}{|c|}{$\begin{array}{l}\text { Discovery Stage } \\
\text { Prevalent Analysis } \\
\text { MGH Cohort }\end{array}$}} & \multicolumn{8}{|c|}{ Prevalent Analysis } & \multicolumn{6}{|c|}{ Incident Analysis } \\
\hline & & & \multicolumn{2}{|c|}{ AFNET Cohort } & \multicolumn{2}{|c|}{ CCAF Cohort } & \multicolumn{2}{|c|}{ CHS Cohort } & \multicolumn{2}{|c|}{ RS Cohort } & \multicolumn{2}{|c|}{ ARIC Cohort } & \multicolumn{2}{|c|}{ CHS Cohort } & \multicolumn{2}{|c|}{ RS Cohort } \\
\hline & $\mathrm{AF}$ & No AF & $\mathrm{AF}$ & No AF & $\mathrm{AF}$ & No AF & $\mathrm{AF}$ & No AF & $\mathrm{AF}$ & No AF & $\mathrm{AF}$ & No AF & $\mathrm{AF}$ & No AF & $\mathrm{AF}$ & No $A F$ \\
\hline No. of subjects & 790 & 1177 & 2145 & 4073 & 496 & 2971 & 66 & 3205 & 309 & 5665 & 743 & 7184 & 765 & 2440 & 542 & 5123 \\
\hline Age, y & $63 \pm 15$ & $67 \pm 13$ & $49 \pm 14$ & $61 \pm 12$ & $58 \pm 11$ & $28 \pm 22$ & $76 \pm 6$ & $72 \pm 5$ & $76 \pm 8$ & $69 \pm 9$ & $57 \pm 5$ & $54 \pm 6$ & $73 \pm 6$ & $72 \pm 5$ & $72 \pm 8$ & $69 \pm 9$ \\
\hline Female, $\%$ & 31 & 47 & 27 & 51 & 24 & 62 & 52 & 39 & 53 & 60 & 40 & 54 & 45 & 37 & 54 & 60 \\
\hline Hypertension, \% & 49 & 57 & 56 & 18 & 54 & Unknown & 52 & 52 & 42 & 33 & 44 & 25 & 59 & 50 & 45 & 32 \\
\hline
\end{tabular}

Data presented as mean \pm SD or $\%$.

the SNP if $P \leq 1 \times 10^{-4}$ in referent subjects. This corresponds to an experiment-wide Hardy-Weinberg significance threshold of $0.005 /$ $41 \approx 1 \times 10^{-4}$. We tested the remaining SNPs for association with AF in the MGH sample using logistic regression assuming an additive genetic model and subsequently adjusted for the genotype of the top SNP to identify independent associations with AF. Significance thresholds were adjusted for multiple testing by use of the Bonferroni method, with an experiment-wide error rate of 0.05 . Thirty-four SNPs passed quality control measures, and therefore, the adjusted significance threshold was $P<0.001(0.05 / 34)$. We then tested SNPs significantly associated with $\mathrm{AF}$, after adjusting for the top SNP in the MGH discovery sample, for association with AF in the AFNET sample. ${ }^{18}$

To identify SNPs that represented distinct AF susceptibility signals, we calculated pairwise linkage disequilibrium measures $r^{2}$ and $\mathrm{D}^{\prime}$ in the MGH and AFNET samples and constructed linkage disequilibrium blocks using Haploview ${ }^{15}$ with previously described definitions. ${ }^{19}$ We inferred haplotypes composed of SNPs located on the same block from unphased data using an expectationmaximization algorithm and tested haplotypes for association with AF using a weighted logistic regression model with adjustment for genotypes of the remaining SNPs that marked separate AF susceptibility signals. ${ }^{20}$ Haplotypes were weighted according to the posterior probability of possible haplotype pairs for each individual subject. ${ }^{20}$

The SNPs associated with AF in both the MGH and AFNET samples that were markers for independent signals were then assessed for association with $\mathrm{AF}$ in the additional replication cohorts by use of logistic regression in samples with prevalent AF (CCAF, CHS, and RS) and Cox proportional hazards regression in samples with incident AF (ARIC, CHS, and RS). Individuals were censored at death, loss to follow-up, or date of last contact. Person-time for the incident analyses began at the time of DNA collection. Associations were adjusted for significant principal components of race for those studies in which population structure was associated with AF. Both prevalent and incident associations were subjected to meta-analysis by an inverse-variance weighted fixed-effects method. ${ }^{21}$

Because indirectly measured haplotype phasing is accompanied by uncertainty, we used the combination of genotypes at SNPs that marked each distinct AF susceptibility signal to define a multimarker variable for each individual. We assessed the association between each multimarker combination of genotypes and $\mathrm{AF}$ relative to the most common combination of genotypes for these SNPs, allowing for separate effects for each genotype combination. The effects were meta-analyzed as described above. In samples with incident AF, the time-dependent area under the receiver operating characteristic curve was estimated for models with and without the multimarker variables included. ${ }^{22}$

For the discovery stage of the analysis in the MGH sample of 790 cases and 1177 referent subjects, we estimated that we would have $41 \%$ power to detect ORs of 1.5 for risk alleles with frequencies of $5 \%$ and $80 \%$ power to detect ORs of 1.5 for risk alleles with frequencies of at least $10 \%$, assuming a 2 -sided $\alpha$-level of 0.001 and population disease prevalence of $1 \% .^{23}$
Statistical analyses were performed with PLINK version $1.06,{ }^{24}$ SAS version 9.1.3 (SAS Institute, Cary, NC), and R version 2.11 (The R Project for Statistical Computing; available at http://www.R-project. org). Regional association plots were prepared with SNAP. ${ }^{18}$

\section{Results}

A total of 790 subjects with AF and 1177 referent subjects from MGH were included in the discovery stage of the analysis. Among the 790 case subjects, 488 were from the MGH lone-AF cohort, and 302 were from the MGH stroke cohort (Table 1). The overall call rate for the 34 SNPs tested for association with $\mathrm{AF}$ was $98.9 \%$.

There was a strong association between AF and SNPs on chromosome 4q25 (Table 2; Figure 1A; online-only Data Supplement Table I). Among the 34 SNPs examined, 15 exceeded the significance threshold of $P<0.001$ after adjustment for age, sex, and hypertension. The most significant association with AF observed at this locus was with the previously reported SNP, rs2200733, with an OR for the minor T allele of 1.80 (95\% CI 1.50 to $2.15, P=1.2 \times 10^{-10}$ ). A second SNP previously reported to confer an independent risk of AF, rs $10033464,{ }^{5}$ was not significantly associated with $\mathrm{AF}$ in the present sample (OR for minor $\mathrm{T}$ allele 1.07, $95 \%$ CI 0.84 to $1.35, P=0.59$ ).

We then performed analyses with adjustment for rs2200733 genotype. The 4 SNPs most significantly associated with $\mathrm{AF}$ were all located within $30 \mathrm{~kb}$ of one another and telomeric to rs2200733 (Figure 1; online-only Data Supplement Table II). Associations between these 4 SNPs and AF after adjustment for age, sex, hypertension, and rs 2200733 genotype (rs17570669: OR for minor T allele $0.60,95 \% \mathrm{CI}$ 0.46 to $0.78, P=2.0 \times 10^{-4} ;$ rs 4124163 : OR for minor G allele $0.56,95 \%$ CI 0.39 to $0.81, P=2.3 \times 10^{-3}$; rs6838973: OR for minor T allele $0.77,95 \% \mathrm{CI} 0.67$ to $0.89, P=3.4 \times 10^{-4}$; and rs3853445: OR for minor C allele $0.75,95 \%$ CI 0.64 to 0.89 , $P=6.9 \times 10^{-4}$ ) were similar to unadjusted associations (online-only Data Supplement Table II). The minor alleles for each of these 4 SNPs were associated with a lower risk of AF. Although rs3853445 and rs6838973 were both associated with AF before adjustment for rs2200733, the association between rs17570669 and AF was not evident until after adjustment for rs2200733. There was a suggestion of a separate signal associated with AF centromeric to rs2200733; however, no SNPs in this region were significantly associated with AF after adjustment for multiple comparisons (Figure 1; online-only Data Supplement Table II). 
Table 2. Fine Mapping of the Locus for AF on Chromosome $4 q 25$ in the Discovery Sample From MGH

\begin{tabular}{|c|c|c|c|c|c|c|}
\hline \multirow[b]{2}{*}{ SNP } & \multirow[b]{2}{*}{ Position } & \multirow[b]{2}{*}{ Minor/Major Allele } & \multicolumn{2}{|c|}{$\begin{array}{l}\text { Minor Allele } \\
\text { Frequency, \% }\end{array}$} & \multirow[b]{2}{*}{ Adjusted OR $(95 \% \mathrm{Cl})^{\star}$} & \multirow[b]{2}{*}{$P$} \\
\hline & & & $\mathrm{AF}$ & No $\mathrm{AF}$ & & \\
\hline rs17554590 & 111782351 & $\mathrm{G} / \mathrm{C}$ & 1.7 & 2.0 & $0.97(0.59-1.61)$ & 0.91 \\
\hline rs2595098 & 111782931 & $\mathrm{~A} / \mathrm{T}$ & 4.8 & 7.1 & $0.63(0.46-0.84)$ & $2.9 \times 10^{-3}$ \\
\hline rs1448818 & 111789672 & $\mathrm{C} / \mathrm{A}$ & 30.1 & 25.7 & $1.24(1.07-1.44)$ & $4.7 \times 10^{-3}$ \\
\hline rs12498374 & 111803868 & $\mathrm{~T} / \mathrm{C}$ & 25.0 & 19.9 & $1.32(1.12-1.55)$ & $7.0 \times 10^{-4}$ \\
\hline rs1448822 & 111820547 & $\mathrm{~A} / \mathrm{G}$ & 36.0 & 30.6 & $1.26(1.09-1.45)$ & $1.5 \times 10^{-3}$ \\
\hline rs13120244 & 111823793 & $A / G$ & 10.0 & 12.4 & $0.83(0.67-1.03)$ & 0.09 \\
\hline rs1900827 & 111843188 & $T / C$ & 40.0 & 31.2 & $1.41(1.23-1.62)$ & $7.8 \times 10^{-7}$ \\
\hline rs4371683 & 111846216 & $\mathrm{~A} / \mathrm{C}$ & 40.1 & 31.6 & $1.40(1.22-1.61)$ & $1.5 \times 10^{-6}$ \\
\hline rs 17042026 & 111851823 & $A / G$ & 26.1 & 16.8 & $1.64(1.39-1.92)$ & $2.8 \times 10^{-9}$ \\
\hline rs12646859 & 111854082 & $G / T$ & 14.1 & 14.7 & $0.99(0.82-1.19)$ & 0.89 \\
\hline rs10222783 & 111854275 & $\mathrm{~T} / \mathrm{C}$ & 3.6 & 2.3 & $1.56(1.02-2.37)$ & 0.04 \\
\hline rs2595085 & 111856222 & $\mathrm{G} / \mathrm{C}$ & 40.2 & 31.8 & $1.40(1.22-1.60)$ & $2.0 \times 10^{-6}$ \\
\hline rs1448817 & 111860502 & $\mathrm{G} / \mathrm{A}$ & 38.0 & 27.6 & $1.51(1.31-1.74)$ & $8.4 \times 10^{-9}$ \\
\hline rs11098090 & 111875857 & $\mathrm{C} / \mathrm{T}$ & 14.8 & 14.2 & $1.04(0.86-1.26)$ & 0.68 \\
\hline rs4307025 & 111876952 & $\mathrm{~A} / \mathrm{T}$ & 37.8 & 27.4 & $1.50(1.31-1.73)$ & $1.2 \times 10^{-8}$ \\
\hline rs2634071 & 111888669 & $\mathrm{~T} / \mathrm{C}$ & 28.9 & 19.2 & $1.60(1.37-1.87)$ & $2.0 \times 10^{-9}$ \\
\hline rs2723333 & 111918540 & $\mathrm{~A} / \mathrm{G}$ & 8.9 & 12.0 & $0.74(0.59-0.92)$ & $6.7 \times 10^{-3}$ \\
\hline rs1906615 & 111921247 & $\mathrm{~T} / \mathrm{G}$ & 30.1 & 20.6 & $1.54(1.32-1.80)$ & $2.6 \times 10^{-8}$ \\
\hline rs2200733 & 111929618 & $T / C$ & 21.5 & 11.7 & $1.80(1.50-2.15)$ & $1.2 \times 10^{-10}$ \\
\hline rs13143308 & 111933868 & $T / G$ & 31.7 & 21.1 & $1.60(1.38-1.86)$ & $9.5 \times 10^{-10}$ \\
\hline rs13105878 & 111937596 & $\mathrm{~A} / \mathrm{C}$ & 7.8 & 10.8 & $0.73(0.58-0.93)$ & $9.7 \times 10^{-3}$ \\
\hline rs11931959 & 111939134 & $\mathrm{G} / \mathrm{A}$ & 38.2 & 28.5 & $1.47(1.28-1.69)$ & $7.8 \times 10^{-8}$ \\
\hline rs10033464 & 111940210 & $T / G$ & 9.2 & 8.5 & $1.07(0.84-1.35)$ & 0.59 \\
\hline rs3855819 & 111946612 & $\mathrm{G} / \mathrm{C}$ & 14.3 & 13.2 & $1.09(0.90-1.32)$ & 0.38 \\
\hline rs6533531 & 111951414 & $G / T$ & 47.3 & 37.0 & $1.43(1.24-1.64)$ & $5.9 \times 10^{-7}$ \\
\hline rs3853444 & 111953585 & $\mathrm{C} / \mathrm{T}$ & 29.7 & 30.8 & $0.95(0.82-1.10)$ & 0.49 \\
\hline rs17570669 & 111956331 & $\mathrm{~T} / \mathrm{A}$ & 7.2 & 8.5 & $0.87(0.67-1.12)$ & 0.28 \\
\hline rs13130446 & 111958605 & $\mathrm{~T} / \mathrm{C}$ & 49.8 & 49.8 & $1.02(0.89-1.16)$ & 0.80 \\
\hline rs10516564 & 111958741 & $\mathrm{G} / \mathrm{A}$ & 29.1 & 30.0 & $0.93(0.80-1.08)$ & 0.33 \\
\hline rs3866834 & 111963462 & $A / G$ & 33.9 & 34.0 & $1.02(0.89-1.18)$ & 0.79 \\
\hline rs4124163 & 111965048 & $\mathrm{G} / \mathrm{A}$ & 3.0 & 5.0 & $0.61(0.42-0.87)$ & $6.1 \times 10^{-3}$ \\
\hline rs3853445 & 111980936 & $\mathrm{C} / \mathrm{T}$ & 20.3 & 26.2 & $0.71(0.61-0.84)$ & $4.1 \times 10^{-5}$ \\
\hline rs6838901 & 111984764 & $\mathrm{C} / \mathrm{G}$ & 13.6 & 14.6 & $0.93(0.77-1.13)$ & 0.47 \\
\hline rs6838973 & 111984944 & $\mathrm{~T} / \mathrm{C}$ & 34.6 & 41.5 & $0.75(0.66-0.86)$ & $4.8 \times 10^{-5}$ \\
\hline
\end{tabular}

Genomic position from NCBI build 36 . OR is the OR that corresponds to the minor allele.

*Adjusted for age, sex, and hypertension.

Characteristics of the 2145 case and 4073 referent subjects in the AFNET sample are displayed in Table 1. In addition to rs2200733, 3 of the 4 SNPs associated with AF in the MGH discovery cohort analysis passed quality control measures with an overall call rate of $94.4 \%$ and were tested for association with AF. As in the MGH sample, with adjustment for age, sex, and hypertension, rs2200733 $\left(P=3.8 \times 10^{-52}\right)$, rs3853445 $\left(P=2.14 \times 10^{-7}\right)$, and $\operatorname{rs} 6838973\left(P=1.45 \times 10^{-8}\right)$ were associated with AF, but $\operatorname{rs} 17570669(P=0.28)$ was not. After additional adjustment for rs2200733 genotype, significant associations with AF were observed for the remaining 3 SNPs (rs17570669: minor T allele OR 0.64, 95\% CI 0.54 to $0.77, P=5.3 \times 10^{-7}$; rs3853445: minor C allele OR 0.82, 95\%
CI 0.74 to $0.91, P=1.1 \times 10^{-4}$; and rs6838973: minor T allele OR $0.81,95 \%$ CI 0.74 to $0.89, P=5.4 \times 10^{-6}$ ).

Pairwise linkage disequilibrium measures revealed that SNPs rs3853445 and rs6838973 were moderately correlated ( $r^{2} 0.43$ and 0.41 in MGH and AFNET, respectively) and located on the same haplotype block in both samples, which suggests that associations between each of these 2 SNPs and AF represented the same signal (online-only Data Supplement Table III). Because rs6838973 was not genotyped directly in the remaining replication samples, rs3853445 was used for subsequent analyses as a marker for this susceptibility signal. In contrast, there was a very low level of correlation between the remaining SNPs $\left(r^{2}<0.11\right.$ for all 
A

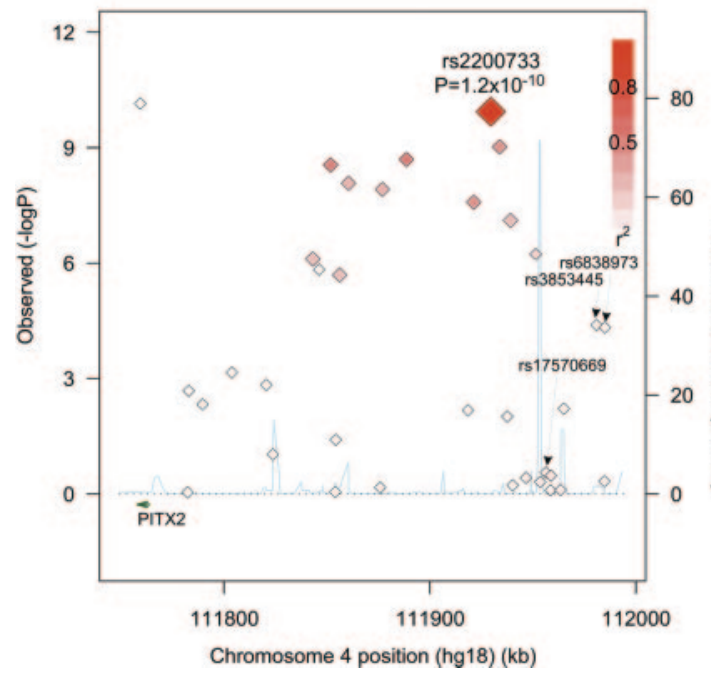

B

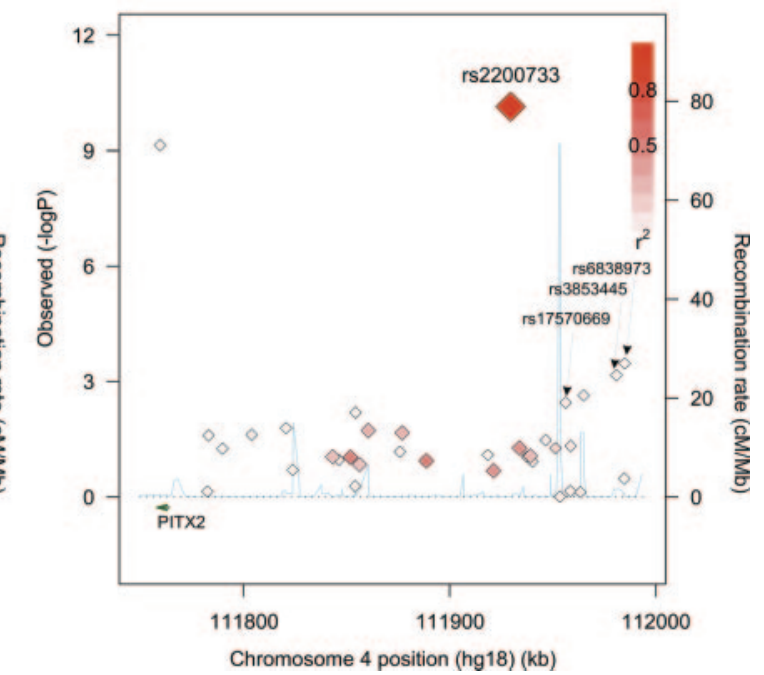

Figure 1. Regional plot of SNPs associated with prevalent AF in the MGH discovery sample. A, Associations between SNPs included in the analysis and AF in the MGH sample, adjusted for age, sex, and hypertension. B, Associations after additional adjustment for rs2200733 genotype, with the rs2200733 position corresponding to the unadjusted association significance level. SNPs are plotted according to their genomic position (NCBI build 36) and $-\log _{10}$ probability value for the association. The intensity of shading for each SNP corresponds to the strength of linkage disequilibrium $\left(r^{2}\right)$ relative to rs2200733. Estimated recombination rates are shown by the blue line. PITX2 is indicated by the dark green arrow. Linkage disequilibrium and recombination rates are based on CEU HapMap release 22. SNPs that were associated with AF after adjustment for rs2200733 genotype and meta-analysis of results from both the MGH and AFNET samples are labeled. Figures were prepared with SNAP. ${ }^{18}$

pairwise comparisons), as expected on the basis of the haplotype-tagging SNP selection method.

We therefore tested the 3 independent susceptibility signals for association with AF by modeling the 2 independent SNPs along with inferred rs3853445 and rs6838973 haplotypes (Table 3). The haplotype consisting of the minor alleles for both rs3853445 and rs6838973 (CT) occurred with a frequency of 23\% in the MGH sample and 26\% in the AFNET sample and conferred reduced odds of $\mathrm{AF}$ relative to the major allele haplotype (TC) after adjustment for rs2200733 and rs 17570669 genotype (combined OR $0.78,95 \%$ CI 0.71 to $0.87, P=1.75 \times 10^{-6}$ ). The remaining 2 susceptibility signals marked by rs2200733 and rs17570669 remained significantly associated with AF in the combined analysis, although the association for rs17570669 was attenuated in the MGH sample.
Associations between SNPs that represented distinct AF susceptibility signals in the MGH and AFNET samples were then tested for replication in the ARIC, CCAF, CHS, and RS study samples. Characteristics of these samples are displayed in Table 1. In general, the associations were replicated in the prevalent AF samples but not in the incident AF samples, although effect estimates tended to be in the same direction as those observed in the discovery sample (Figure 2).

We then calculated the relative risk of AF for each multimarker combination of genotypes for SNPs that tagged each of the $3 \mathrm{AF}$ susceptibility signals relative to the most common combination of genotypes in each of the study samples (Figure 3). The multimarker analysis indicated a graded risk of AF that generally corresponded to the number of $\mathrm{AF}$ risk alleles, although the risks varied within strata defined by numbers of risk alleles, and CIs overlapped for

Table 3. Associations Between AF and rs2200733, rs17570669, and Common rs3853445 | rs6838973 Haplotypes in the MGH and AFNET Samples

\begin{tabular}{|c|c|c|c|c|c|c|c|c|}
\hline \multirow[b]{2}{*}{ Variant } & \multirow{2}{*}{$\begin{array}{l}\text { Haplotype } \\
\text { Frequency }\end{array}$} & \multicolumn{2}{|c|}{ MGH } & \multirow{2}{*}{$\begin{array}{l}\text { Haplotype } \\
\text { Frequency }\end{array}$} & \multicolumn{2}{|c|}{ AFNET } & \multicolumn{2}{|c|}{ Combined $†$} \\
\hline & & OR $(95 \% \mathrm{Cl})$ & $P$ & & OR $(95 \% \mathrm{Cl})$ & $P$ & OR $(95 \% \mathrm{Cl})$ & $P$ \\
\hline rs2200733 & $\ldots$ & $1.87(1.54-2.27)$ & $2.4 \times 10^{-10}$ & $\ldots$ & $2.64(2.32-3.00)$ & $3.4 \times 10^{-49}$ & $2.37(2.13-2.64)$ & $3.1 \times 10^{-56}$ \\
\hline rs17570669 & $\ldots$ & $0.74(0.55-1.01)$ & 0.06 & $\ldots$ & $0.70(0.58-0.85)$ & $2.8 \times 10^{-4}$ & $0.71(0.61-0.84)$ & $4.3 \times 10^{-5}$ \\
\hline \multicolumn{9}{|c|}{ rs3853445 | rs6838973 } \\
\hline \multicolumn{9}{|c|}{ Haplotype } \\
\hline TC & 0.60 & Reference & $\ldots$ & 0.56 & Reference & $\ldots$ & Reference & $\ldots$ \\
\hline TT & 0.16 & $0.92(0.75-1.13)$ & 0.45 & 0.17 & $0.99(0.86-1.13)$ & 0.89 & $0.97(0.87-1.09)$ & 0.59 \\
\hline $\mathrm{CC}$ & 0.01 & $1.24(0.58-2.66)$ & 0.57 & 0.01 & $1.87(1.21-2.91)$ & $5.0 \times 10^{-3}$ & $1.69(1.16-2.47)$ & $7.0 \times 10^{-3}$ \\
\hline $\mathrm{CT}^{*}$ & 0.23 & $0.75(0.63-0.90)$ & $1.6 \times 10^{-3}$ & 0.26 & $0.80(0.71-0.90)$ & $2.7 \times 10^{-4}$ & $0.78(0.71-0.87)$ & $1.75 \times 10^{-6}$ \\
\hline
\end{tabular}

Adjusted for age, sex, and hypertension. OR is the OR that corresponds to the minor allele or specified haplotype.

${ }^{*}$ Composed of the minor alleles for each respective SNP.

†Meta-analysis performed using a fixed-effects method. 


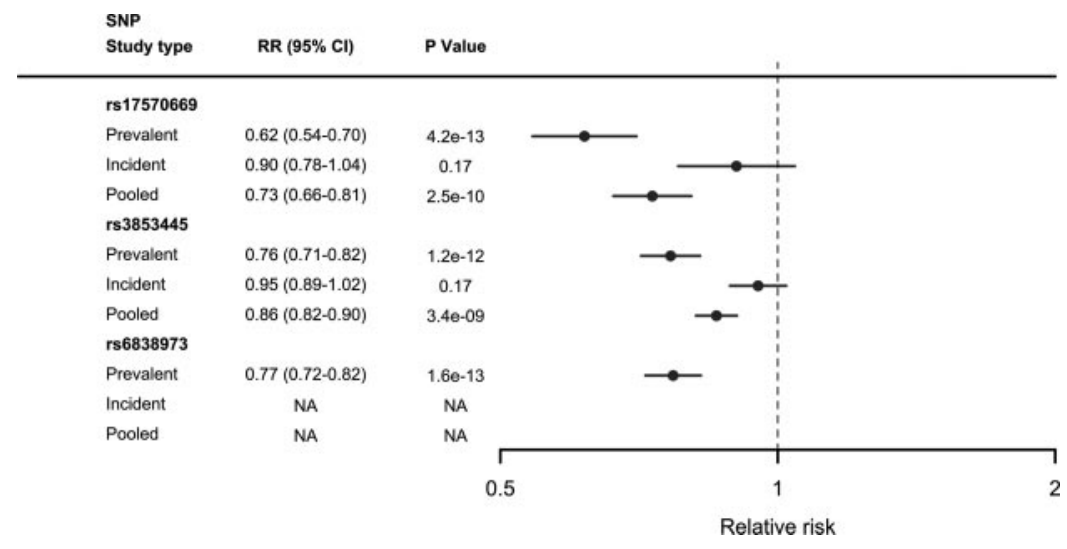

Figure 2. SNPs associated with AF after adjustment for rs2200733 genotype. SNPs associated with AF after adjustment for rs2200733 genotype in the MGH discovery sample were tested for association in the replication samples. The meta-analyzed effects are plotted according to prevalent (OR), incident (hazard ratio), or pooled (relative risk [RR]) analysis status. Associations were adjusted for age, sex, and hypertension (MGH, AFNET, ARIC, $\mathrm{CHS}$, and RS) or sex only (CCAF). Samples with prevalent AF included MGH, AFNET, CHS, CCAF, and RS. Samples with incident AF included ARIC, CHS, and RS. NA indicates not available. many of the multimarker groups owing to small sample sizes. The relative risks of $\mathrm{AF}$ for the 3 most frequent rs2200733/rs17570669/rs3853445 genotype combinations (relative to the most common genotype combination $\mathrm{CC} /$ $\mathrm{AA} / \mathrm{TT}$, composed of $4 \mathrm{AF}$ risk alleles; $38 \%$ of subjects) were 0.90 (95\% CI 0.82 to $0.99, \mathrm{CC} / \mathrm{AA} / \mathrm{CT}$ [ 3 risk alleles, $26 \%$ of subjects]), 1.74 (95\% CI 1.48 to 2.03 , CT/AA/CT [ 4 risk alleles, $5 \%$ of subjects]), and 2.26 (95\% CI 2.02 to $2.53, \mathrm{CT} / \mathrm{AA} / \mathrm{TT}$ [ 5 risk alleles, $10 \%$ of subjects]). The greatest relative risk was observed with the combination comprised of both AF risk alleles at each of the 3 SNPs, TT/AA/TT, which occurred in approximately $1 \%$ of subjects (relative risk 6.02, 95\% CI 4.56 to 7.96). The associations, stratified by prevalent or incident status, are displayed in online-only Data Supplement Figure II.

In samples with incident $\mathrm{AF}$, the time-dependent area under the curve for a model with age, sex, and hypertension was 0.70 (95\% CI 0.69 to 0.72 ) and 0.68 (95\% CI 0.66 to 0.70) over the follow-up periods in ARIC and RS, respectively. The area under the curve increased to $0.72(95 \% \mathrm{Cl}$ 0.70 to 0.73 ) and 0.70 (95\% CI 0.68 to 0.72 ), respectively, after the addition of the multimarker allele combinations.

\section{Discussion}

In the present study sample of subjects from MGH, the previously reported SNP, rs2200733, remained the variant most significantly associated with $\mathrm{AF}$ even after consideration of other SNPs at the chromosome $4 \mathrm{q} 25$ locus. In addition to this signal, we identified 2 novel AF susceptibility signals after adjustment for rs2200733 genotype in a metaanalysis of 5856 subjects with AF and 31838 without AF, all of whom were of European ancestry. A multimarker risk score composed of SNPs that tagged each of these $3 \mathrm{AF}$ susceptibility signals on chromosome $4 \mathrm{q} 25$ identified indi-

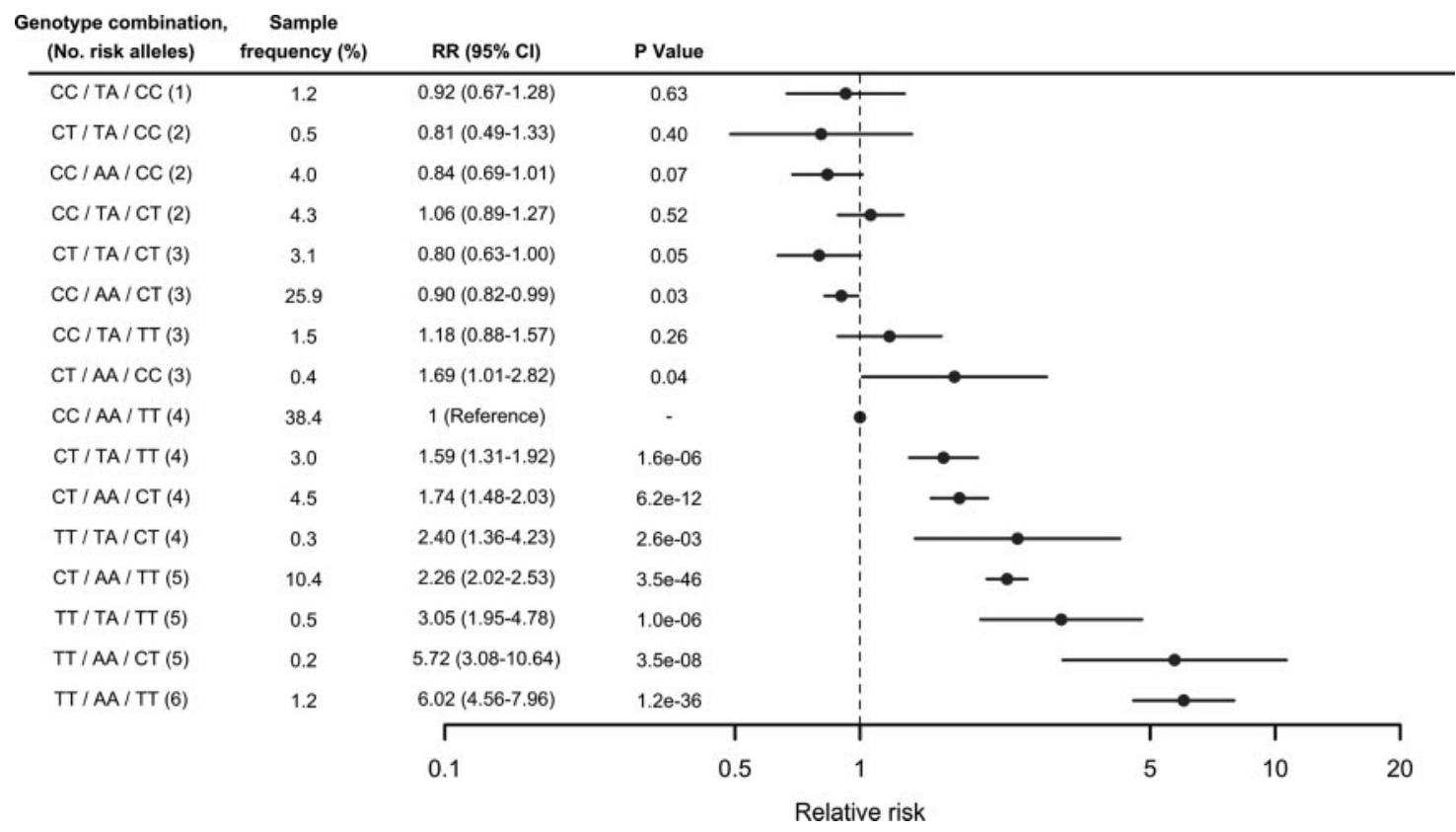

Figure 3. Multimarker risk score for AF based on combined rs2200733, rs17570669, and rs3853445 genotypes. The meta-analyzed relative risk (RR) of AF for each multimarker combination of rs2200733, rs17570669, and rs3853445 genotypes relative to the most common multimarker combination is shown. Only multimarker combinations with an average sample frequency of $\geq 0.2 \%$ are displayed, although the effects were adjusted for all potential combinations, as well as age, sex, and hypertension, or sex only (CCAF). Individuals with incomplete genotypes were not included. Risk alleles for AF were the minor T allele for rs2200733, the major A allele for rs17570669, and the major T allele for rs3853445. 
viduals at varying risk of developing $\mathrm{AF}$, which approximately corresponded to the number of AF risk alleles present.

The present results reinforce the association between chromosome $4 \mathrm{q} 25$ and $\mathrm{AF}$ and extend the knowledge base by defining the genetic architecture of this locus and its relation to AF. ${ }^{5-8}$ Specifically, SNPs rs17570669, rs3853445, and rs6838973 were confined to a $30-\mathrm{kb}$ region from the $200-\mathrm{kb}$ region assayed and located within $50 \mathrm{~kb}$ telomeric of rs2200733. The locus studied in the present analysis is marked by regions that appear to be phylogenetically conserved (online-only Data Supplement Figure III). ${ }^{25}$ Indeed, there is emerging evidence that highly conserved noncoding regions may act as regulatory elements and underlie phenotypic diversity. ${ }^{26,27}$ However, the mechanism by which genetic variation at the chromosome $4 \mathrm{q} 25$ locus leads to AF remains unknown.

The lack of significant association in the incident AF samples between AF and SNPs rs17570669 and rs3853445, after adjustment for rs2200733 genotype, may reflect reduced power in the incident stratum, an absence of true association when modeled in this fashion, interactions between variants and unmeasured clinical factors that differ between prevalent and incident $\mathrm{AF}$, or other phenotypic heterogeneity between prevalent and incident AF. A multimarker risk score composed of AF risk alleles at SNPs that tagged these 3 susceptibility signals identified individuals predisposed to the development of AF, which raises the possibility that consideration of multiple genetic variants at the chromosome $4 \mathrm{q} 25$ locus may help improve risk stratification of individuals at risk for AF. ${ }^{28}$ Whether the consideration of the 3 signals identified in the present analysis will contribute to $\mathrm{AF}$ prediction in the context of additional variants associated with $\mathrm{AF}^{7-9,29,30}$ is presently unclear but merits examination in larger prospective data sets.

\section{Study Limitations}

The present analysis was restricted to individuals of European descent, and therefore, the findings may not be generalizable to individuals of other races and ethnicities. Although we could not assess for population stratification in the MGH and AFNET samples, the relative homogeneity of the present study cohorts limits the likelihood of such confounding. Furthermore, we adjusted analyses for population structure in replication cohorts when there was evidence of association with AF. We did not restrict the age of subjects included in the analysis. Although the chromosome $4 \mathrm{q} 25$ region has been associated with AF in subjects with a diverse spectrum of presumed causes, ${ }^{7,9,31,32}$ including those with lone $\mathrm{AF}^{9}$ and typical forms of $\mathrm{AF},{ }^{7}$ sources of heterogeneity in the discovery cohort that were not accounted for may have affected the SNPs selected for replication. The haplotype and multimarker risk score analyses represent multiple testing, and several subgroups were of small sample size, as reflected by the wide CIs that accompanied some effect estimates; positive associations may represent "winner's curse." 33 Although we did not adjust for multiple testing at this stage, the observed associations are supported by the fact that SNPs tested in these analyses were selected after conservative Bonferroni-adjusted association thresholds in the discovery analysis. Moreover, patterns of association for these subgroups were consistent across independent study samples. We are unable to rule out longerdistance associations at the locus beyond the boundaries of the present SNP selection region. Lastly, although we cannot exclude the possibility that all of the identified SNPs merely tag a single, common element associated with AF, the low correlation between the SNPs identified in the present analysis and the haplotype association analysis suggest that these SNPs represent 3 independent signals at the chromosome $4 q 25$ locus that affect AF risk.

\section{Conclusions}

We confirmed the strong association between AF and rs2200733 at the chromosome 4q25 locus and identified 2 novel disease susceptibility signals that are associated with AF. Simultaneous consideration of these signals identifies individuals with an increased risk for AF.

\section{Acknowledgments}

The authors thank the staff and participants of the AFNET/KORA, ARIC, CHS, CCAF, MGH, and RS studies for their important contributions.

\section{Sources of Funding}

MGH: This study was funded by grants to Dr Ellinor from the Deane Institute for Integrative Research in Atrial Fibrillation and Stroke and grants from the National Institutes of Health (NIH) to Dr Rosand (R01NS059727), Dr Furie (P50NS051343), Dr Lubitz (T32HL007575), and Drs Ellinor and Benjamin (RO1HL092577, RC1HL101056, and DA027021). AFNET: The study was also supported by the German Federal Ministry of Education and Research (BMBF) in the context of the German National Genome Research Network (NGFN), the German National Competence Network on Atrial Fibrillation (AFNET), the Leducq Foundation (07-CVD 03) by grants to Dr Kääb (01GS0499, 01GI0204, and 01GS0838). KORA S4: The KORA platform is funded by the Helmholtz Zentrum München, the BMBF partly in the context of the NGFN, and the State of Bavaria, and as part of LMUinnovativ. ARIC: ARIC is conducted as a collaborative study supported by National Heart, Lung, and Blood Institute (NHLBI) contracts N01HC-55015, N01-HC-55016, N01-HC-55018, N01-HC-55019, N01HC-55020, N01-HC-55021, N01-HC-55022, R01HL087641, R01HL59367, R01HL086694, and RC1 HL101056; National Human Genome Research Institute contract U01HG004402; and NIH contract HHSN268200625226C. The present analysis was also supported by American Heart Association grant 09SDG2280087 and NHLBI/NIH grant 1RC1HL099452. CCAF: The CCAF is supported by R01 HL090620 from the NHLBI (Drs Chung, Barnard, and Smith); NIH/National Center for Research Resources, Clinical Translational Science Award 1UL-RR024989 (Dr Chung); Heart and Vascular Institute, Department of Cardiovascular Medicine, Cleveland Clinic (Dr Chung); and P50 HL077107 from the NHLBI (Dr Barnard). CHS: The CHS research reported in this article was supported by contract Nos. N01-HC-85079 through N01-HC-85086, N01-HC-35129, N01 HC-15103, N01 HC-55222, N01-HC-75150, and N01-HC-45133 and grant Nos. U01 HL080295 and R01 HL087652 from the NHLBI, with additional contribution from the National Institute of Neurological Disorders and Stroke. DNA handling and genotyping were supported in part by National Center for Research Resources grant M01-RR00425 to the Cedars-Sinai General Clinical Research Center Genotyping Core and by National Institute of Diabetes and Digestive and Kidney Diseases grant DK063491 to the Southern California Diabetes Endocrinology Research Center. A full list of principal CHS investigators and institutions can be found at http://www.chs-nhlbi.org/pi.htm. RS: The genome-wide association database of the RS was funded through the Netherlands Organization of Scientific Research (No. 
175.010.2005.011). The RS is supported by the Erasmus Medical Center and Erasmus University, Rotterdam; the Netherlands Organization for Scientific Research; the Netherlands Organization for Health Research and Development; the Research Institute for Diseases in the Elderly; the Ministry of Education, Culture and Science; the Ministry for Health, Welfare and Sports; the European Commission (DG XII); and the Municipality of Rotterdam.

\section{Disclosures}

Dr Greenberg serves as a consultant/advisory board member for Hoffman-LaRoche. Dr Boerwinkle serves as a consultant/advisory board member for Celera Diagnostics. Dr Smith serves as a consultant/advisory board member for Esperion Therapeutics. The remaining authors report no conflicts.

\section{References}

1. Fuster V, Ryden LE, Cannom DS, Crijns HJ, Curtis AB, Ellenbogen KA, Halperin JL, Le Heuzey JY, Kay GN, Lowe JE, Olsson SB, Prystowsky EN, Tamargo JL, Wann S, Smith SC Jr, Jacobs AK, Adams CD, Anderson JL, Antman EM, Halperin JL, Hunt SA, Nishimura R, Ornato JP, Page RL, Riegel B, Priori SG, Blanc JJ, Budaj A, Camm AJ, Dean V, Deckers JW, Despres C, Dickstein K, Lekakis J, McGregor K, Metra M, Morais J, Osterspey A, Tamargo JL, Zamorano JL. ACC/AHA/ESC 2006 guidelines for the management of patients with atrial fibrillation: a report of the American College of Cardiology/American Heart Association Task Force on Practice Guidelines and the European Society of Cardiology Committee for Practice Guidelines (Writing Committee to Revise the 2001 Guidelines for the Management of Patients With Atrial Fibrillation): developed in collaboration with the European Heart Rhythm Association and the Heart Rhythm Society. Circulation. 2006;114:e257-e354.

2. Lee WC, Lamas GA, Balu S, Spalding J, Wang Q, Pashos CL. Direct treatment cost of atrial fibrillation in the elderly American population: a Medicare perspective. J Med Econ. 2008;11:281-298.

3. Fox CS, Parise H, D'Agostino RB Sr, Lloyd-Jones DM, Vasan RS, Wang TJ, Levy D, Wolf PA, Benjamin EJ. Parental atrial fibrillation as a risk factor for atrial fibrillation in offspring. JAMA. 2004;291:2851-2855.

4. Arnar DO, Thorvaldsson S, Manolio TA, Thorgeirsson G, Kristjansson K, Hakonarson H, Stefansson K. Familial aggregation of atrial fibrillation in Iceland. Eur Heart J. 2006;27:708-712.

5. Gudbjartsson DF, Arnar DO, Helgadottir A, Gretarsdottir S, Holm H, Sigurdsson A, Jonasdottir A, Baker A, Thorleifsson G, Kristjansson K, Palsson A, Blondal T, Sulem P, Backman VM, Hardarson GA, Palsdottir E, Helgason A, Sigurjonsdottir R, Sverrisson JT, Kostulas K, Ng MC, Baum L, So WY, Wong KS, Chan JC, Furie KL, Greenberg SM, Sale M, Kelly P, MacRae CA, Smith EE, Rosand J, Hillert J, Ma RC, Ellinor PT, Thorgeirsson G, Gulcher JR, Kong A, Thorsteinsdottir U, Stefansson K. Variants conferring risk of atrial fibrillation on chromosome $4 \mathrm{q} 25$. Nature. 2007;448:353-357.

6. Kaab S, Darbar D, van Noord C, Dupuis J, Pfeufer A, Newton-Cheh C, Schnabel R, Makino S, Sinner MF, Kannankeril PJ, Beckmann BM, Choudry S, Donahue BS, Heeringa J, Perz S, Lunetta KL, Larson MG, Levy D, MacRae CA, Ruskin JN, Wacker A, Schomig A, Wichmann HE, Steinbeck G, Meitinger T, Uitterlinden AG, Witteman JC, Roden DM, Benjamin EJ, Ellinor PT. Large scale replication and meta-analysis of variants on chromosome 4q25 associated with atrial fibrillation. Eur Heart J. 2009;30:813-819.

7. Benjamin EJ, Rice KM, Arking DE, Pfeufer A, van Noord C, Smith AV, Schnabel RB, Bis JC, Boerwinkle E, Sinner MF, Dehghan A, Lubitz SA, D'Agostino RB Sr, Lumley T, Ehret GB, Heeringa J, Aspelund T, Newton-Cheh C, Larson MG, Marciante KD, Soliman EZ, Rivadeneira F, Wang TJ, Eiriksdottir G, Levy D, Psaty BM, Li M, Chamberlain AM, Hofman A, Vasan RS, Harris TB, Rotter JI, Kao WH, Agarwal SK, Stricker BH, Wang K, Launer LJ, Smith NL, Chakravarti A, Uitterlinden AG, Wolf PA, Sotoodehnia N, Kottgen A, van Duijn CM, Meitinger T, Mueller M, Perz S, Steinbeck G, Wichmann HE, Lunetta KL, Heckbert SR, Gudnason V, Alonso A, Kaab S, Ellinor PT, Witteman JC. Variants in ZFHX3 are associated with atrial fibrillation in individuals of European ancestry. Nat Genet. 2009;41:879-881.

8. Gudbjartsson DF, Holm H, Gretarsdottir S, Thorleifsson G, Walters GB, Thorgeirsson G, Gulcher J, Mathiesen EB, Njolstad I, Nyrnes A, Wilsgaard T, Hald EM, Hveem K, Stoltenberg C, Kucera G, Stubblefield T, Carter S, Roden D, Ng MC, Baum L, So WY, Wong KS, Chan JC, Gieger C, Wichmann HE, Gschwendtner A, Dichgans M, Kuhlenbaumer
G, Berger K, Ringelstein EB, Bevan S, Markus HS, Kostulas K, Hillert J, Sveinbjornsdottir S, Valdimarsson EM, Lochen ML, Ma RC, Darbar D, Kong A, Arnar DO, Thorsteinsdottir U, Stefansson K. A sequence variant in ZFHX3 on 16q22 associates with atrial fibrillation and ischemic stroke. Nat Genet. 2009;41:876-878.

9. Ellinor PT, Lunetta KL, Glazer NL, Pfeufer A, Alonso A, Chung MK, Sinner MF, de Bakker PI, Mueller M, Lubitz SA, Fox E, Darbar D, Smith NL, Smith JD, Schnabel R, Soliman EZ, Rice K, Van Wagoner DR, Beckmann BM, van Noord C, Wang K, Ehret GB, Rotter JI, Hazen S, Steinbeck G, Makino S, Nelis M, Milan DJ, Perz S, Esko T, Kottgen A, Moebus S, Newton-Cheh C, Li M, Mohlenkamp S, Wang TJ, Kao WH, Vasan RS, Nothen MM, MacRae CA, Levy D, Boerwinkle E, Metspalu A, Topol EJ, Chakravarti A, Psaty BM, Roden D, Meitlinger T, Wichmann HE, Witteman JC, Barnard J, Arking DE, Benjamin EJ, Heckbert SR, Kääb S. Common variants in KCNN3 are associated with lone atrial fibrillation. Nat Genet. 2010;42:240-244.

10. Nabauer M, Gerth A, Limbourg T, Schneider S, Oeff M, Kirchhof P, Goette A, Lewalter T, Ravens U, Meinertz T, Breithardt G, Steinbeck G. The Registry of the German Competence NETwork on Atrial Fibrillation: patient characteristics and initial management. Europace. 2009;11: 423-434.

11. Wichmann HE, Gieger C, Illig T. KORA-gen: resource for population genetics, controls and a broad spectrum of disease phenotypes. Gesundheitswesen. 2005;67(suppl 1):S26-S30.

12. The ARIC Investigators. The Atherosclerosis Risk in Communities (ARIC) Study: design and objectives. Am J Epidemiol. 1989;129: 687-702.

13. Fried LP, Borhani NO, Enright P, Furberg CD, Gardin JM, Kronmal RA, Kuller LH, Manolio TA, Mittelmark MB, Newman A, O'Leary DH, Psaty BM, Rautaharju P, Tracy RP, Weiler PG. The Cardiovascular Health Study: design and rationale. Ann Epidemiol. 1991;1:263-276.

14. Hofman A, Breteler MM, van Duijn CM, Krestin GP, Pols HA, Stricker BH, Tiemeier H, Uitterlinden AG, Vingerling JR, Witteman JC. The Rotterdam Study: objectives and design update. Eur J Epidemiol. 2007; 22:819-829.

15. Barrett JC, Fry B, Maller J, Daly MJ. Haploview: analysis and visualization of LD and haplotype maps. Bioinformatics. 2005;21:263-265.

16. Servin B, Stephens M. Imputation-based analysis of association studies: candidate regions and quantitative traits. PLoS Genet. 2007;3:e114.

17. Wigginton JE, Cutler DJ, Abecasis GR. A note on exact tests of HardyWeinberg equilibrium. Am J Hum Genet. 2005;76:887-893.

18. Johnson AD, Handsaker RE, Pulit SL, Nizzari MM, O'Donnell CJ, de Bakker PI. SNAP: a web-based tool for identification and annotation of proxy SNPs using HapMap. Bioinformatics. 2008;24:2938-2939.

19. Gabriel SB, Schaffner SF, Nguyen H, Moore JM, Roy J, Blumenstiel B, Higgins J, DeFelice M, Lochner A, Faggart M, Liu-Cordero SN, Rotimi C, Adeyemo A, Cooper R, Ward R, Lander ES, Daly MJ, Altshuler D. The structure of haplotype blocks in the human genome. Science. 2002; 296:2225-2229.

20. Sinnwell JP, Schaid DJ, Yu Z. Haplo Stats 1.4.4. User Manual. 2009. Available at: http://mayoresearch.mayo.edu/mayo/research/schaid_lab/ software.cfm. Accessed August 3, 2010.

21. Egger M, Smith GD, Altman DG. Systematic Reviews in Health Care: Meta-Analysis in Context. 2nd ed. London, United Kingdom: BMJ; 2001.

22. Pencina MJ, D'Agostino RB. Overall C as a measure of discrimination in survival analysis: model specific population value and confidence interval estimation. Stat Med. 2004;23:2109-2123.

23. Purcell S, Cherny SS, Sham PC. Genetic Power Calculator: design of linkage and association genetic mapping studies of complex traits. Bioinformatics. 2003;19:149-150.

24. Purcell S, Neale B, Todd-Brown K, Thomas L, Ferreira MA, Bender D, Maller J, Sklar P, de Bakker PI, Daly MJ, Sham PC. PLINK: a tool set for whole-genome association and population-based linkage analyses. Am J Hum Genet. 2007;81:559-575.

25. Kent WJ, Sugnet CW, Furey TS, Roskin KM, Pringle TH, Zahler AM, Haussler D. The human genome browser at UCSC. Genome Res. 2002; 12:996-1006.

26. Nobrega MA, Ovcharenko I, Afzal V, Rubin EM. Scanning human gene deserts for long-range enhancers. Science. 2003;302:413.

27. Pennacchio LA, Ahituv N, Moses AM, Prabhakar S, Nobrega MA, Shoukry M, Minovitsky S, Dubchak I, Holt A, Lewis KD, Plajzer-Frick I, Akiyama J, De Val S, Afzal V, Black BL, Couronne O, Eisen MB, Visel A, Rubin EM. In vivo enhancer analysis of human conserved non-coding sequences. Nature. 2006;444:499-502. 
28. Schnabel RB, Sullivan LM, Levy D, Pencina MJ, Massaro JM, D'Agostino RB Sr, Newton-Cheh C, Yamamoto JF, Magnani JW, Tadros TM, Kannel WB, Wang TJ, Ellinor PT, Wolf PA, Vasan RS, Benjamin EJ. Development of a risk score for atrial fibrillation (Framingham Heart Study): a community-based cohort study. Lancet. 2009;373:739-745.

29. Holm H, Gudbjartsson DF, Arnar DO, Thorleifsson G, Thorgeirsson G, Stefansdottir H, Gudjonsson SA, Jonasdottir A, Mathiesen EB, Njolstad I, Nyrnes A, Wilsgaard T, Hald EM, Hveem K, Stoltenberg C, Lochen ML, Kong A, Thorsteinsdottir U, Stefansson K. Several common variants modulate heart rate, PR interval and QRS duration. Nat Genet. 2010;42: $117-122$.

30. Pfeufer A, van Noord C, Marciante KD, Arking DE, Larson MG, Smith AV, Tarasov KV, Muller M, Sotoodehnia N, Sinner MF, Verwoert GC, Li M, Kao WH, Kottgen A, Coresh J, Bis JC, Psaty BM, Rice K, Rotter JI, Rivadeneira F, Hofman A, Kors JA, Stricker BH, Uitterlinden AG, van Duijn CM, Beckmann BM, Sauter W, Gieger C, Lubitz SA, Newton-Cheh C, Wang TJ, Magnani JW, Schnabel RB, Chung MK, Barnard J, Smith JD, Van Wagoner DR, Vasan RS, Aspelund T, Eiriksdottir G, Harris TB, Launer LJ, Najjar SS, Lakatta E, Schlessinger D, Uda
M, Abecasis GR, Muller-Myhsok B, Ehret GB, Boerwinkle E, Chakravarti A, Soliman EZ, Lunetta KL, Perz S, Wichmann HE, Meitinger T, Levy D, Gudnason V, Ellinor PT, Sanna S, Kaab S, Witteman JC, Alonso A, Benjamin EJ, Heckbert SR. Genome-wide association study of PR interval. Nat Genet. 2010;42:153-159.

31. Body SC, Collard CD, Shernan SK, Fox AA, Liu KY, Ritchie MD, Perry TE, Muehlschlegel JD, Aranki S, Donahue BS, Pretorius M, Estrada JC, Ellinor PT, Newton-Cheh C, Seidman CE, Seidman JG, Herman DS, Lichtner P, Meitinger T, Pfeufer A, Kaab S, Brown NJ, Roden DM, Darbar D. Variation in the 4q25 chromosomal locus predicts atrial fibrillation after coronary artery bypass graft surgery. Circ Cardiovasc Genet. 2009;2:499-506.

32. Viviani Anselmi C, Novelli V, Roncarati R, Malovini A, Bellazzi R, Bronzini R, Marchese G, Condorelli G, Montenero AS, Puca AA. Association of rs2200733 at 4q25 with atrial flutter/fibrillation diseases in an Italian population. Heart. 2008;94:1394-1396.

33. Nakaoka H, Inoue I. Meta-analysis of genetic association studies: methodologies, between-study heterogeneity and winner's curse. J Hum Genet. 2009;54:615-623.

\section{CLINICAL PERSPECTIVE}

Atrial fibrillation (AF) is a heritable disorder with evidence of genetic susceptibility. Common single-nucleotide polymorphisms (SNPs) in a noncoding region on chromosome 4q25 have been associated with AF. We sought to determine whether more than 1 AF susceptibility signal exists at this locus. We genotyped SNPs at the chromosome 4q25 locus in 790 case subjects and 1177 control subjects. After adjustment for the genotype of the most significantly associated SNP, the SNPs that remained significantly associated with AF were replicated in an additional 5066 subjects with AF and 30661 without AF. We identified 3 distinct AF susceptibility signals, 2 of which have not been described previously. A multimarker risk score composed of SNPs tagging each of these 3 AF susceptibility signals identified individuals at varying risk of developing AF. Among the 1\% of subjects homozygous for AF risk alleles at SNPs tagging each susceptibility signal, the risk of $\mathrm{AF}$ was markedly increased relative to those with the most common genotypes at these SNPs (relative risk $6.02,95 \%$ confidence interval 4.56 to $7.96, P=1.2 \times 10^{-36}$ ). Consideration of multiple susceptibility signals at the chromosome 4q25 locus identifies individuals with a markedly increased risk of AF and may facilitate the localization of regulatory elements at this locus with particular biological relevance in the pathogenesis of AF. 


\section{SUPPLEMENTAL MATERIAL}

Independent Susceptibility Markers for Atrial Fibrillation on Chromosome 4q25

CIRCULATIONAHA/2009/886440 


\section{INDEX FOR SUPPLEMENTAL MATERIAL}

\section{Page Section}

3 Detailed description of study samples.

6 Supplemental Table 1. Fine mapping of the locus for atrial fibrillation on chromosome 4q25 in the MGH study sample stratified by case subject cohort.

7 Supplemental Table 2. Fine mapping of the locus for atrial fibrillation on chromosome 4q25 in the MGH discovery sample after adjusting for rs2200733 genotype.

8 Supplemental Table 3. Pairwise linkage disequilibrium measures for rs2200733, rs17570669, rs6838973, and rs3853445 in the MGH, AFNET, and HapMap CEU samples.

8 Supplemental Figure 1. Minor allele frequencies of SNPs tagging distinct atrial fibrillation susceptibility signals.

10 Supplemental Figure 2. Multimarker risk score for AF based on combined rs2200733, rs 17570669 , and rs 3853445 genotypes, stratified by prevalent or incident AF status.

11 Supplemental figure 3. Phylogenetic conservation at the chromosome 4q25 locus.

12 Supplemental References 


\section{SUPPLEMENTAL METHODS}

The Massachusetts General Hospital (MGH) lone AF sample consisted of patients with AF referred to the Cardiac Arrhythmia Service starting in June 2001 in whom AF was documented by electrocardiogram before 66 years of age. Exclusion criteria included any history of structural heart disease, rheumatic heart disease, hyperthyroidism, myocardial infarction, or heart failure prior to the onset of AF. Each patient underwent a standardized interview and physical examination to identify relevant clinical characteristics, a 12-lead electrocardiogram, and blood draw for collection of DNA. The MGH Stroke sample included patients with AF by electrocardiogram or history who were admitted to the MGH Stroke service between January 1998 and July 2006 with an acute ischemic or hemorrhagic stroke confirmed by brain computed tomography or magnetic resonance imaging. Patients with primary subarachnoid hemorrhage or intracerebral hemorrhage secondary to head trauma, tumor, vascular malformation, or vasculitis were excluded. Referent subjects from MGH were recruited from a large, primary care practice of greater than 18,000 patients serving the hospital catchment area. All subjects, or a family informant, were interviewed prospectively regarding medical, medication, social and family history. Absence of AF was prospectively documented through interview and from review of medical records including all available electrocardiograms.

The German Competence Network for Atrial Fibrillation (AFNET) is a national registry of AF patients. ${ }^{1}$ AF was confirmed by electrocardiogram, and DNA samples were collected from patients with AF in whom onset occurred before 60 years of age. Patients with New York Heart Association class III or IV heart failure, moderate to severe valvular disease, or hyperthyroidism were excluded from the study. Referent subjects were derived from a community-based epidemiologic survey study conducted between 1999 and 2001 of persons living in or near the city of Augsburg, Southern Germany (KORA S4). ${ }^{2}$ Study participants were equally distributed male and female residents of German nationality between 25 to 74 years of age. Referent 
subjects were excluded if they reported a history of AF, had signs or symptoms of AF on physical examination, or absence of sinus rhythm on a required electrocardiogram.

The Cleveland Clinic Lone AF Study (CCAF) is comprised of subjects with lone AF, defined as those with AF in the absence of significant structural heart disease with recurring or persistent lone AF, absence of clinical evidence of coronary artery stenosis or documented stenosis $\leq 50 \%$, and a left ventricular ejection fraction (LVEF) $\geq 50 \%$. Subjects with heart failure, significant valvular disease (>2+ valvular regurgitation, any valvular stenosis), prior myocardial infarction, prior percutaneous coronary intervention, prior coronary artery bypass graft, congenital heart disease, hypertrophic cardiomyopathy, aortic dissection or repair, were excluded. All subjects from Studies $64,65,66$ and 67 in the Illumina iControl database were used as the referent controls.

The Atherosclerosis Risk in Communities (ARIC) study is a prospective populationbased study of subjects in the United States (73\% of European descent) aged 45 to 64 at enrollment, recruited from 4 US communities (suburbs of Minneapolis, Minnesota; Washington County, Maryland; Jackson, Mississippi; and Forsyth County, North Carolina) between 19871989 to investigate the epidemiology of cardiovascular disease. ${ }^{3}$ Participants underwent electrocardiograms at baseline and at each follow-up exam (3 exams; 1 exam every 3 years). Incident AF was classified as the first occurrence of AF through 2005 as identified from electrocardiograms at study visits, hospital discharge codes or death certificates (ICD-9 code 427.31 or 427.32 , or ICD-10 code 148). The sensitivity and positive predictive value of hospital discharge codes for the diagnosis of incident AF, as determined after review of hospital discharge summaries in a sample of ARIC participants, was close to $90 \% .{ }^{4}$ Only subjects of self-reported European ancestry were included in this analysis; thus, subjects recruited from Jackson, Mississippi, and a small group of subjects from Forsyth County, North Carolina, were not included. 
The Rotterdam Study (RS) is a community-based study of elderly individuals from a suburb of Rotterdam with a focus on identifying determinants of health and cardiovascular, neurogeriatric, bone, and eye diseases. Participants age $\geq 55$ years were examined up to 4 times every 3 years. ${ }^{5} \mathrm{AF}$ was diagnosed based on study visit electrocardiograms, review of hospital discharge information, and general practitioner diagnoses. AF was verified by 2 physicians and disagreements settled by review of a cardiologist. ${ }^{6}$

The Cardiovascular Health Study (CHS) is a prospective population-based study of cardiovascular disease in individuals 65 years or older recruited from 4 Field Centers (Forsyth County, NC; Sacramento County, CA; Washington County, MD; Pittsburgh, PA). ${ }^{7}$ Prevalent AF was that which was present on the baseline electrocardiogram. Incident AF was classified at the occasion of first AF identified during an annual CHS electrocardiogram or by ICD-9 code on a hospital discharge. 


\section{SUPPLEMENTAL TABLES}

Supplemental Table 1. Fine mapping of the locus for atrial fibrillation on chromosome $4 q 25$ in the MGH study sample stratified by case subject cohort.

\begin{tabular}{|c|c|c|c|c|}
\hline \multirow{2}{*}{ SNP } & \multicolumn{2}{|c|}{$\begin{array}{c}\text { Lone } \\
\text { ( } \mathrm{N}=488 \text { cases, } 727 \text { referent) }\end{array}$} & \multicolumn{2}{|c|}{$\begin{array}{c}\text { Stroke } \\
\text { ( } \mathrm{N}=302 \text { cases, } 450 \text { referent) }\end{array}$} \\
\hline & $\begin{array}{l}\text { Odds ratio } \\
(95 \% \mathrm{Cl})\end{array}$ & $P$ Value & $\begin{array}{l}\text { Odds ratio } \\
(95 \% \mathrm{Cl})\end{array}$ & $P$ Value \\
\hline rs17554590 & $0.66(0.27-1.58)$ & 0.35 & $1.07(0.50-2.31)$ & 0.86 \\
\hline rs2595098 & $0.70(0.44-1.11)$ & 0.13 & $0.64(0.38-1.07)$ & 0.09 \\
\hline rs1448818 & $1.20(0.96-1.50)$ & 0.12 & $1.23(0.95-1.60)$ & 0.12 \\
\hline rs12498374 & $1.26(0.98-1.61)$ & 0.07 & $1.37(1.04-1.81)$ & 0.03 \\
\hline rs1448822 & $1.23(0.99-1.52)$ & 0.06 & $1.18(0.92-1.53)$ & 0.19 \\
\hline rs13120244 & $0.74(0.52-1.05)$ & 0.09 & $1.10(0.77-1.56)$ & 0.61 \\
\hline rs1900827 & $1.79(1.45-2.22)$ & $1.1 \times 10^{-7}$ & $0.97(0.76-1.23)$ & 0.79 \\
\hline rs4371683 & $1.79(1.44-2.22)$ & $1.5 \times 10^{-7}$ & $0.96(0.76-1.23)$ & 0.76 \\
\hline rs17042026 & $1.99(1.54-2.55)$ & $9.6 \times 10^{-8}$ & $1.14(0.85-1.51)$ & 0.39 \\
\hline rs12646859 & $1.23(0.90-1.67)$ & 0.19 & $0.80(0.58-1.09)$ & 0.16 \\
\hline rs10222783 & $2.67(1.36-5.22)$ & $4.2 \times 10^{-3}$ & $0.98(0.47-2.06)$ & 0.96 \\
\hline rs2595085 & $1.79(1.44-2.22)$ & $1.3 \times 10^{-7}$ & $0.96(0.75-1.22)$ & 0.71 \\
\hline rs1448817 & $1.94(1.56-2.43)$ & $4.3 \times 10^{-9}$ & $1.02(0.80-1.30)$ & 0.87 \\
\hline rs11098090 & $1.30(0.97-1.76)$ & 0.08 & $0.77(0.56-1.07)$ & 0.12 \\
\hline rs4307025 & $1.95(1.56-2.44)$ & $3.5 \times 10^{-9}$ & $1.01(0.79-1.29)$ & 0.92 \\
\hline rs2634071 & $2.13(1.68-2.72)$ & $8.5 \times 10^{-10}$ & $0.98(0.74-1.29)$ & 0.89 \\
\hline rs2723333 & $0.81(0.57-1.15)$ & 0.24 & $0.80(0.56-1.16)$ & 0.24 \\
\hline rs1906615 & $1.97(1.56-2.50)$ & $2.1 \times 10^{-8}$ & $0.96(0.73-1.25)$ & 0.75 \\
\hline rs2200733 & $2.26(1.72-2.97)$ & $5.5 \times 10^{-9}$ & $1.17(0.85-1.63)$ & 0.34 \\
\hline rs13143308 & $2.11(1.67-2.67)$ & $4.9 \times 10^{-10}$ & $0.97(0.74-1.27)$ & 0.83 \\
\hline rs13105878 & $0.49(0.33-0.73)$ & $4.3 \times 10^{-4}$ & 1.09 (0.75-1.59) & 0.65 \\
\hline rs11931959 & $1.60(1.29-1.99)$ & $1.9 \times 10^{-5}$ & $1.14(0.89-1.45)$ & 0.31 \\
\hline rs10033464 & $1.46(1.02-2.08)$ & 0.04 & $0.60(0.39-0.92)$ & 0.02 \\
\hline rs3855819 & $1.03(0.77-1.38)$ & 0.85 & $1.01(0.73-1.41)$ & 0.95 \\
\hline rs6533531 & $1.87(1.49-2.34)$ & $5.2 \times 10^{-8}$ & $0.93(0.74-1.18)$ & 0.57 \\
\hline rs3853444 & $0.97(0.78-1.22)$ & 0.7989 & $1.00(0.77-1.29)$ & 0.99 \\
\hline rs17570669 & $0.67(0.44-1.02)$ & 0.06 & $1.11(0.73-1.69)$ & 0.61 \\
\hline rs13130446 & $1.08(0.88-1.32)$ & 0.48 & $1.02(0.81-1.29)$ & 0.86 \\
\hline rs10516564 & $0.87(0.70-1.09)$ & 0.22 & $0.98(0.76-1.26)$ & 0.88 \\
\hline rs3866834 & $1.06(0.84-1.32)$ & 0.63 & $0.99(0.78-1.25)$ & 0.92 \\
\hline rs4124163 & $0.43(0.24-0.77)$ & $4.7 \times 10^{-3}$ & 0.95 (0.54-1.69) & 0.87 \\
\hline rs3853445 & $0.75(0.59-0.97)$ & 0.03 & $0.72(0.54-0.94)$ & 0.02 \\
\hline rs6838901 & $0.85(0.63-1.14)$ & 0.28 & $0.84(0.60-1.18)$ & 0.31 \\
\hline rs6838973 & $0.73(0.59-0.90)$ & $3.9 \times 10^{-3}$ & $0.74(0.59-0.94)$ & 0.01 \\
\hline
\end{tabular}

Adjusted for age, sex, hypertension. 
Supplemental Table 2. Fine mapping of the locus for atrial fibrillation on chromosome 4q25 in the MGH discovery sample after adjusting for rs2200733 genotype.

\begin{tabular}{|c|c|c|c|c|c|c|}
\hline \multirow[t]{2}{*}{ SNP } & \multicolumn{2}{|c|}{ Adjusted for rs 2200733} & \multicolumn{2}{|c|}{$\begin{array}{c}\text { Adjusted for rs2200733, } \\
\text { age, and sex }\end{array}$} & \multicolumn{2}{|c|}{$\begin{array}{c}\text { Adjusted for rs2200733, } \\
\text { age, sex, and } \\
\text { hypertension }\end{array}$} \\
\hline & $\begin{array}{c}\text { Odds ratio } \\
(95 \% \mathrm{Cl})\end{array}$ & $P$ Value & $\begin{array}{c}\text { Odds ratio } \\
(95 \% \mathrm{Cl})\end{array}$ & $P$ Value & $\begin{array}{l}\text { Odds ratio } \\
(95 \% \mathrm{Cl})\end{array}$ & $P$ Value \\
\hline rs17554590 & $1.00(0.61-1.62)$ & 0.98 & $1.10(0.66-1.83)$ & 0.71 & $1.10(0.66-1.83)$ & 0.72 \\
\hline rs2595098 & $0.76(0.57-1.01)$ & 0.06 & $0.72(0.53-0.98)$ & 0.03 & $0.71(0.52-0.96)$ & 0.03 \\
\hline rs1448818 & $1.16(1.01-1.35)$ & 0.04 & $1.16(0.99-1.35)$ & 0.07 & $1.16(1.00-1.35)$ & 0.06 \\
\hline rs12498374 & $1.24(1.05-1.45)$ & $9.1 \times 10^{-3}$ & $1.20(1.02-1.42)$ & 0.03 & $1.21(1.03-1.43)$ & 0.02 \\
\hline rs1448822 & $1.21(1.05-1.39)$ & $7.8 \times 10^{-3}$ & $1.19(1.03-1.37)$ & 0.02 & $1.20(1.03-1.38)$ & 0.02 \\
\hline rs13120244 & $0.82(0.67-1.02)$ & 0.07 & $0.87(0.70-1.08)$ & 0.20 & $0.87(0.69-1.08)$ & 0.20 \\
\hline rs1900827 & $1.14(0.97-1.34)$ & & & & & \\
\hline rs4371683 & $1.13(0.97-1.33)$ & & & & & \\
\hline rs17042026 & $1.24(1.00-1.55)$ & 0.05 & & & & 09 \\
\hline rs12646859 & $1.04(0.86-1.25)$ & 0.71 & $1.05(0.87-1.28)$ & 0.60 & $1.07(0.88-1.29)$ & 0.52 \\
\hline rs10222783 & $1.92(1.27-2.89)$ & & $1.81(1.18-2.79)$ & & $1.82(1.18-2.80)$ & \\
\hline rs2595085 & $1.12(0.96-1.31)$ & 0.16 & $1.12(0.95-1.33)$ & & $1.13(0.96-1.33)$ & 0.14 \\
\hline rs1448817 & $1.26(1.06-1.50)$ & $8.4 \times 10^{-3}$ & $1.24(1.0$ & 0.02 & & 0.02 \\
\hline rs11098090 & $1.22(1.01-1.47)$ & 0.04 & 1.19( & & $1.20(0.99-1.4$ & \\
\hline rs4307025 & $1.27(1.07-1.51)$ & $7.4 \times 10^{-3}$ & $1.23(1.03-1.48)$ & 0.03 & $1.24(1.03-1.4$ & 0.02 \\
\hline rs2634071 & $1.20(0.94-1.53)$ & & & & & \\
\hline rs2723333 & $0.81(0.65-1.01)$ & & & & & 0.08 \\
\hline rs1906615 & & & & & & \\
\hline rs13143308 & $1.31(1.05-1.63)$ & 0.02 & 1.2 & 0.06 & 1.26 & 0.05 \\
\hline rs13105878 & $0.78(0.61-0.98)$ & 0.0 & $-1.03)$ & 0.09 & & 0.09 \\
\hline rs11931959 & $1.20(1.01-1.44)$ & & $1.18(0$ & & & 0. \\
\hline rs10033464 & $1.24(0.99-1.56)$ & 0.06 & $1.20(0.95-1.53)$ & 0.13 & $1.21(0.95-1.54)$ & 0.12 \\
\hline rs3855819 & $1.26(1.04-1.52)$ & & $1.24(1.02-1.51)$ & & $1.24(1.02-1.51)$ & 0.03 \\
\hline rs6533531 & $1.22(1.04-1.43)$ & 0.02 & $1.18(0.99-1.39)$ & 0.06 & $1.18(1.00-1.40)$ & 0.05 \\
\hline rs3853444 & $1.02(0.88-1.17)$ & & $1.00(0.86-1.16)$ & 0.99 & $1.00(0.86-1.16)$ & 0.98 \\
\hline rs17570669 & $0.60(0.46-0.78)$ & $2.0 \times 10^{-4}$ & $0.67(0.50-0.88)$ & $4.7 \times 10^{-3}$ & $0.66(0.49-0.87)$ & $3.6 \times 10^{-3}$ \\
\hline rs13130446 & $1.02(0.90-1.16)$ & 0.77 & $1.02(0.89-1.17)$ & 0.75 & $1.03(0.90-1.18)$ & 0.70 \\
\hline rs10516564 & $0.86(0.75-1.00)$ & 0.05 & $0.86(0.74-1.00)$ & 0.05 & $0.86(0.74-1.00)$ & 0.05 \\
\hline rs3866834 & $1.01(0.88-1.16)$ & 0.86 & $1.02(0.89-1.18)$ & 0.75 & $1.02(0.89-1.18)$ & 0.75 \\
\hline rs4124163 & $0.55(0.39-0.79)$ & $1.0 \times 10^{-3}$ & $0.56(0.39-0.81)$ & $2.3 \times 10^{-3}$ & $0.56(0.39-0.81)$ & $2.3 \times 10^{-3}$ \\
\hline rs3853445 & $0.76(0.65-0.90)$ & $8.6 \times 10^{-4}$ & $0.75(0.64-0.89)$ & $7.8 \times 10^{-4}$ & $0.75(0.64-0.89)$ & $6.9 \times 10^{-4}$ \\
\hline rs6838901 & $0.88(0.73-1.07)$ & 0.20 & $0.91(0.75-1.11)$ & 0.36 & $0.91(0.74-1.11)$ & 0.33 \\
\hline rs6838973 & $0.77(0.68-0.88)$ & $1.8 \times 10^{-4}$ & $0.78(0.68-0.90)$ & $4.6 \times 10^{-4}$ & 0.77 (0.67-0.89) & $3.4 \times 10^{-4}$ \\
\hline
\end{tabular}

Genomic position from NCBI build 36. 
Supplemental Table 3. Pairwise linkage disequilibrium measures for rs2200733, rs17570669, rs6838973, and rs3853445 in the MGH, AFNET, and HapMap CEU samples.

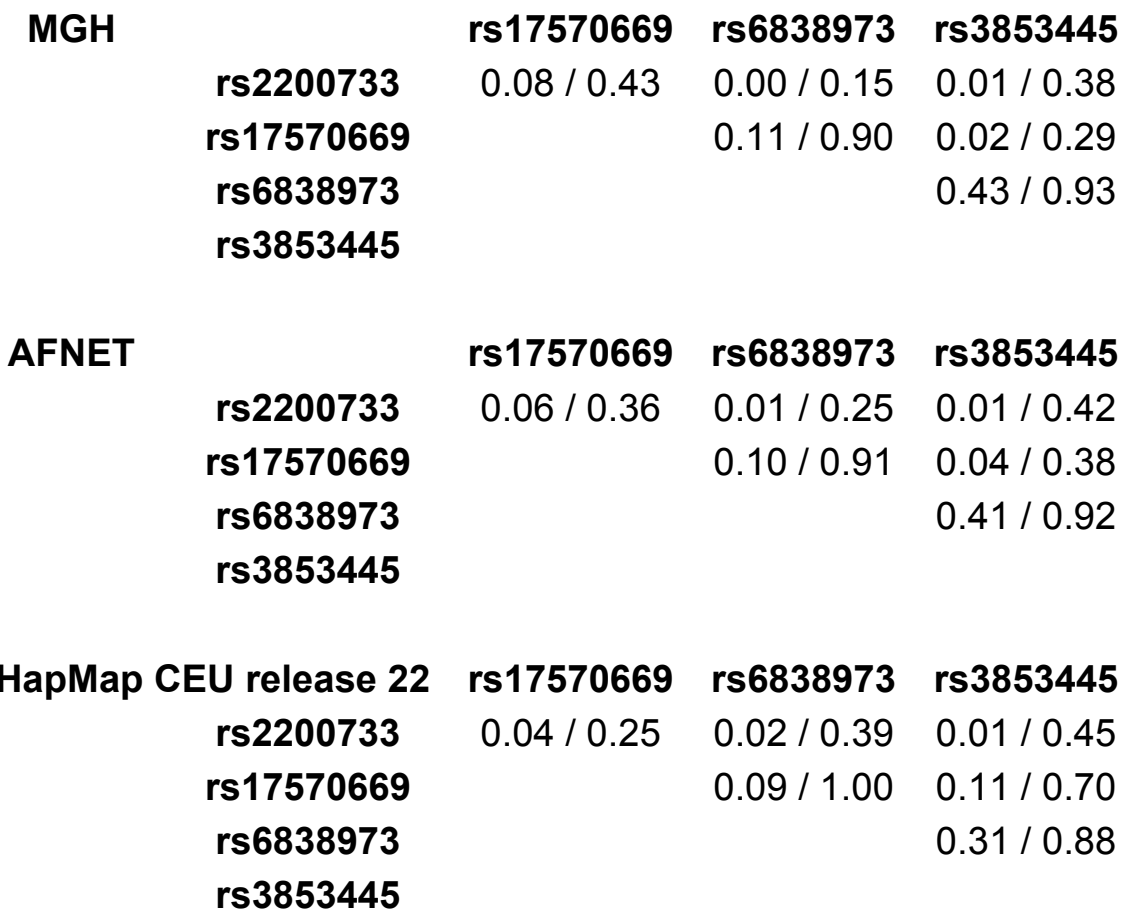

Linkage disequilibrium values are represented as $r^{2} / D^{\prime}$. 


\section{SUPPLEMENTAL FIGURES}

Supplemental Figure 1. Minor allele frequencies of SNPs tagging distinct atrial fibrillation susceptibility signals.
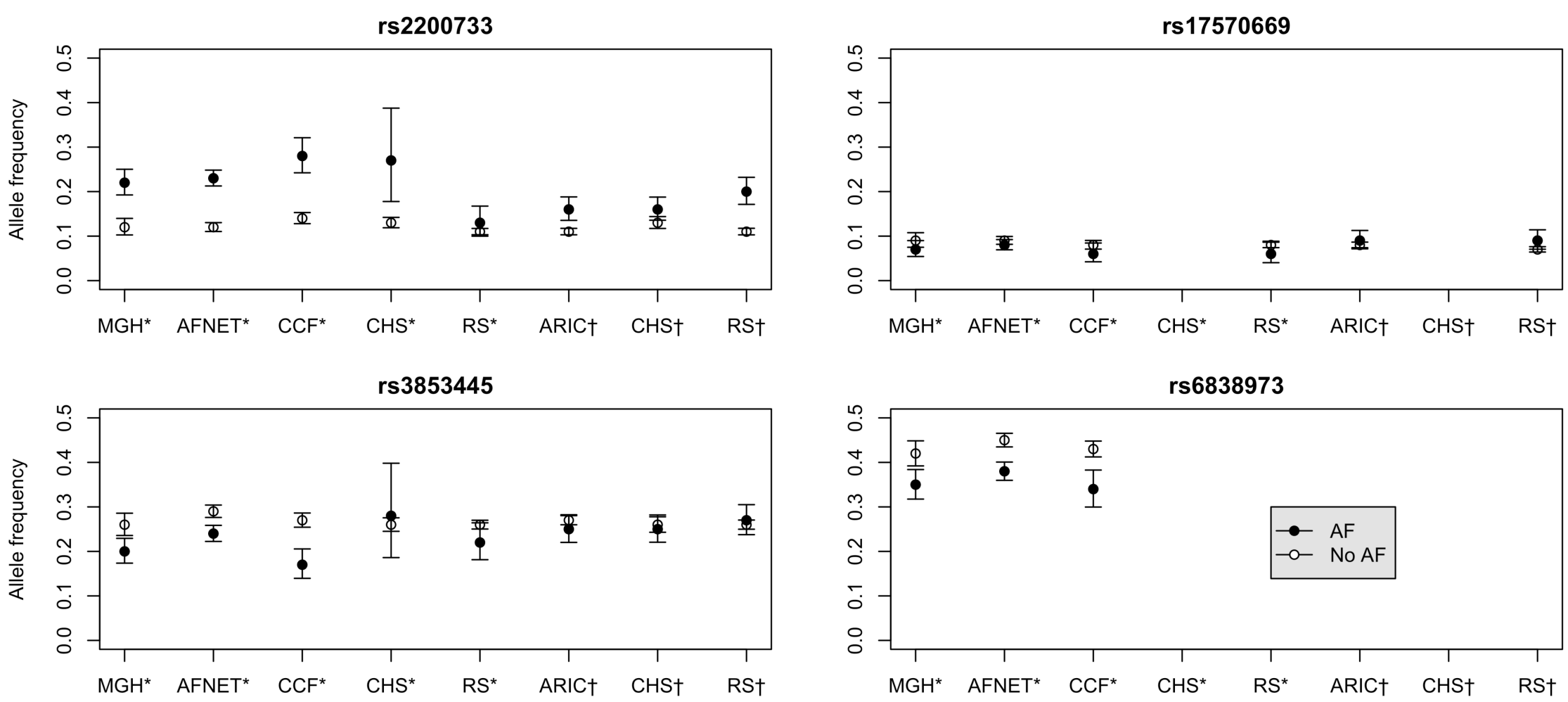

The SNPs rs3853445 and rs6838973 tag the same AF susceptibility signal.

*Prevalent sample

†Incident sample 
Supplemental Figure 2. Multimarker risk score for AF based on combined rs2200733, rs17570669, and rs3853445 genotypes, stratified by prevalent or incident AF status.

The meta-analyzed relative risk of AF for each multimarker combination of rs2200733, rs 17570669 , and rs 3853445 genotypes relative to the most common multimarker combination are shown. Only multimarker combinations with an average sample frequency of $\geq 0.2 \%$ are displayed, though the effects are adjusted for all potential combinations, as well as age, sex, and hypertension, or sex only (CCAF). Subjects with incomplete genotypes were not included. Risk alleles for AF were the T allele for rs2200733, the A allele for rs 17570669, and the T allele for rs3853445. Samples with prevalent AF included MGH, AFNET, CCAF, CHS, and RS. Samples with incident AF included ARIC and RS. Relative risks correspond to odds ratios (prevalent AF) and hazard ratios (incident AF).

\section{Genotype combination,}

(No. risk alleles)

$\operatorname{RR}(95 \% \mathrm{Cl}) \quad$ P Value

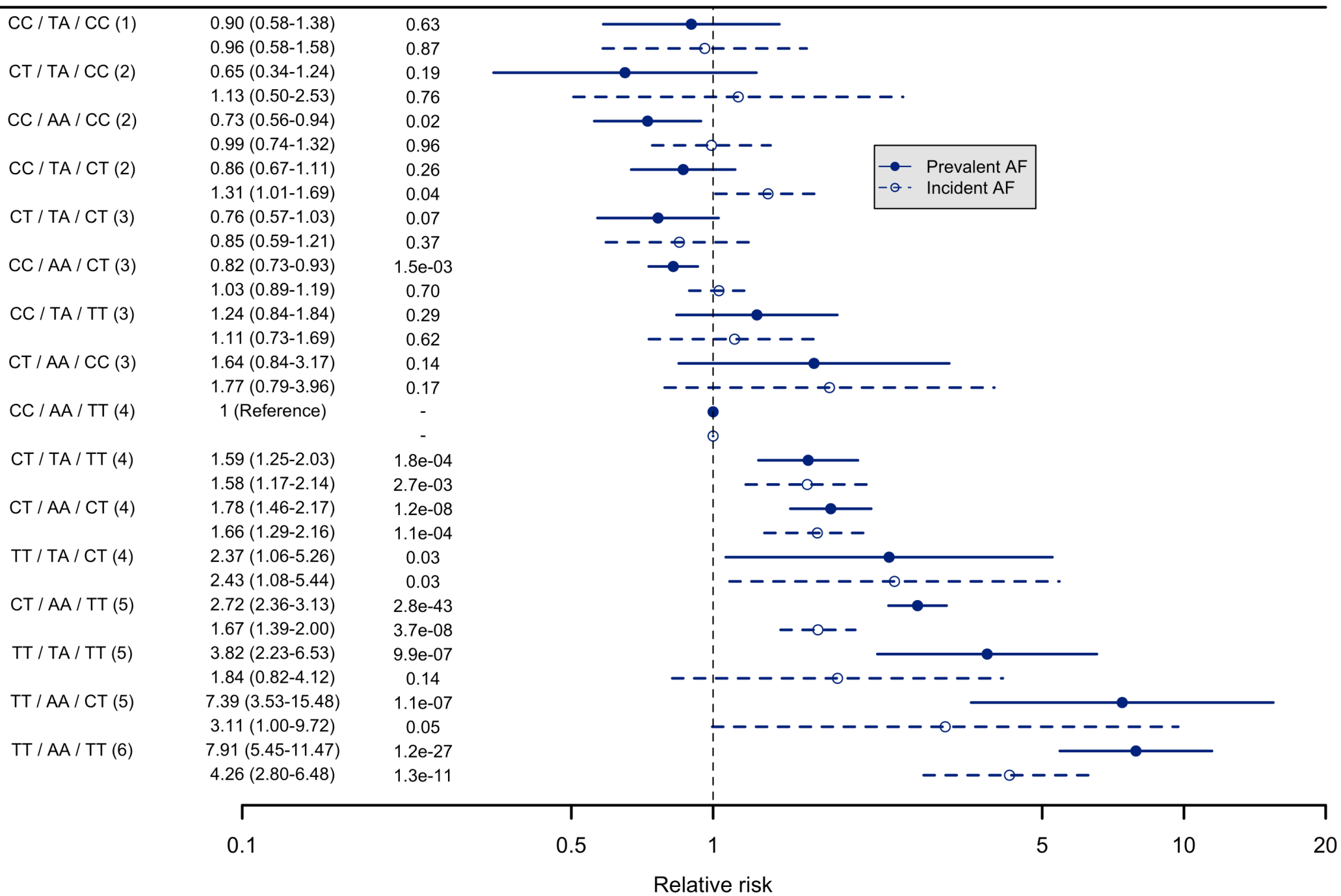


Supplemental Figure 3. Phylogenetic conservation at the chromosome 4q25 locus.

Pairwise alignment of genomic sequences of 16 mammalian and vertebrate species to the human genome (hg18) are plotted between positions 111,728,759-112,034,944 at the chromosome 4q25 locus. Blue peaks correspond to regions of high sequence conservation, and are reflected in the multi-species alignment in green. Pale yellow lines indicate uncertainty in the genomic sequence. Three isoforms of PITX2 are displayed on the plot. SNPs tagging distinct AF susceptibility signals are indicated. Plot generated using the UCSC genome browser. $^{8}$

Position 111750000 I

111800000 I

111850000 |

111900000 ।

111950000 I

112000000 |

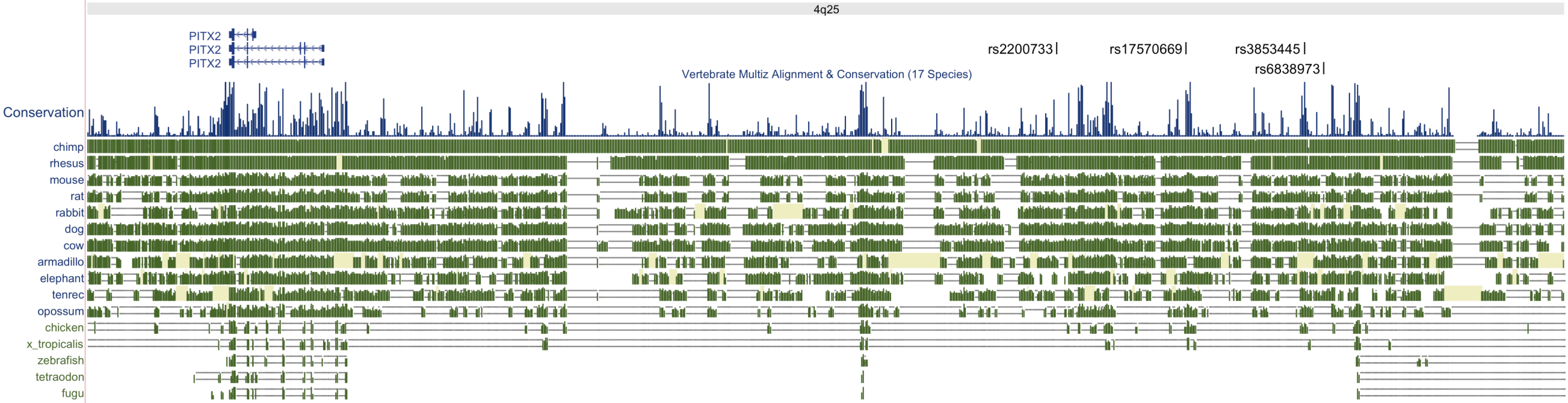




\section{Supplemental References}

1. Nabauer M, Gerth A, Limbourg T, Schneider S, Oeff M, Kirchhof P, Goette A, Lewalter T, Ravens U, Meinertz T, Breithardt G, Steinbeck G. The Registry of the German Competence NETwork on Atrial Fibrillation: patient characteristics and initial management. Europace. 2009;11:423-434.

2. Wichmann HE, Gieger C, Illig T. KORA-gen--resource for population genetics, controls and a broad spectrum of disease phenotypes. Gesundheitswesen. 2005;67 Suppl $1:$ S26-30.

3. The Atherosclerosis Risk in Communities (ARIC) Study: design and objectives. The ARIC investigators. Am J Epidemiol. 1989;129:687-702.

4. Alonso A, Agarwal SK, Soliman EZ, Ambrose M, Chamberlain AM, Prineas RJ, Folsom AR. Incidence of atrial fibrillation in whites and African-Americans: the Atherosclerosis Risk in Communities (ARIC) study. Am Heart J. 2009;158:111-117.

5. Hofman A, Breteler MM, van Duijn CM, Krestin GP, Pols HA, Stricker BH, Tiemeier H, Uitterlinden AG, Vingerling JR, Witteman JC. The Rotterdam Study: objectives and design update. Eur J Epidemiol. 2007;22:819-829.

6. Heeringa J, van der Kuip DA, Hofman A, Kors JA, van Herpen G, Stricker BH, Stijnen T, Lip GY, Witteman JC. Prevalence, incidence and lifetime risk of atrial fibrillation: the Rotterdam study. Eur Heart J. 2006;27:949-953.

7. Fried LP, Borhani NO, Enright P, Furberg CD, Gardin JM, Kronmal RA, Kuller LH, Manolio TA, Mittelmark MB, Newman A, O'Leary DH, Psaty BM, Rautaharju P, Tracy RP, Weiler PG. The Cardiovascular Health Study: design and rationale. Ann Epidemiol. 1991;1:263-276.

8. Kent WJ, Sugnet CW, Furey TS, Roskin KM, Pringle TH, Zahler AM, Haussler D. The human genome browser at UCSC. Genome Res. 2002;12:996-1006. 


\section{Circulation}

\section{Independent Susceptibility Markers for Atrial Fibrillation on Chromosome 4q25}

Steven A. Lubitz, Moritz F. Sinner, Kathryn L. Lunetta, Seiko Makino, Arne Pfeufer, Rosanna Rahman, Caroline E. Veltman, John Barnard, Joshua C. Bis, Stephan P. Danik, Akshata Sonni, Marisa A. Shea, Federica del Monte, Siegfried Perz, Martina Müller, Annette Peters, Steven M. Greenberg, Karen L. Furie, Charlotte van Noord, Eric Boerwinkle, Bruno H.C. Stricker, Jacqueline Witteman, Jonathan D. Smith, Mina K. Chung, Susan R. Heckbert, Emelia J.

Benjamin, Jonathan Rosand, Dan E. Arking, Alvaro Alonso, Stefan Kääb and Patrick T. Ellinor

Circulation. 2010;122:976-984; originally published online August 23, 2010; doi: 10.1161/CIRCULATIONAHA.109.886440

Circulation is published by the American Heart Association, 7272 Greenville Avenue, Dallas, TX 75231

Copyright $\odot 2010$ American Heart Association, Inc. All rights reserved.

Print ISSN: 0009-7322. Online ISSN: 1524-4539

The online version of this article, along with updated information and services, is located on the World Wide Web at:

http://circ.ahajournals.org/content/122/10/976

Data Supplement (unedited) at:

http://circ.ahajournals.org/content/suppl/2010/08/20/CIRCULATIONAHA.109.886440.DC1.html

\footnotetext{
Permissions: Requests for permissions to reproduce figures, tables, or portions of articles originally published in Circulation can be obtained via RightsLink, a service of the Copyright Clearance Center, not the Editorial Office. Once the online version of the published article for which permission is being requested is located, click Request Permissions in the middle column of the Web page under Services. Further information about this process is available in the Permissions and Rights Question and Answer document.
}

Reprints: Information about reprints can be found online at: http://www.lww.com/reprints

Subscriptions: Information about subscribing to Circulation is online at: http://circ.ahajournals.org//subscriptions/ 